Review

\title{
Coordination Polymers and Metal Organic Frameworks Derived from 1,2,4-Triazole Amino Acid Linkers
}

\author{
Anil D. Naik, Marinela M. Dîrtu, Antoine P. Railliet, Jacqueline Marchand-Brynaert and \\ Yann Garcia * \\ Institute of Condensed Matter and Nanosciences, Université Catholique de Louvain, \\ Place L. Pasteur 1, 1348 Louvain-la-Neuve, Belgium; E-Mails: anil.naik@uclouvain.be (A.D.N.); \\ marinela.dirtu@uclouvain.be (M.M.D.); antoine.railliet@uclouvain.be (A.P.R.); \\ jacqueline.marchand@uclouvain.be (J.M.-B.) \\ * Author to whom correspondence should be addressed; E-Mail: yann.garcia@uclouvain.be; \\ Tel.: +32-10-472-826; Fax: +32-10-472-330.
}

Received: 5 July 2011; in revised form: 20 September 2011 / Accepted: 7 October 2011 / Published: 11 October 2011

\begin{abstract}
The perceptible appearance of biomolecules as prospective building blocks in the architecture of coordination polymers (CPs) and metal-organic frameworks (MOFs) are redolent of their inclusion in the synthon/tecton library of reticular chemistry. In this frame, for the first time a synthetic strategy has been established for amine derivatization in amino acids into 1,2,4-triazoles. A set of novel 1,2,4-triazole derivatized amino acids were introduced as superlative precursors in the design of 1D coordination polymers, 2D chiral helicates and 3D metal-organic frameworks. Applications associated with these compounds are diverse and include gas adsorption-porosity partitioning, soft sacrificial matrix for morphology and phase selective cadmium oxide synthesis, $\mathrm{Fe}^{\mathrm{II}}$ spin crossover materials, zinc- $\beta$-lactamases inhibitors, logistics for generation of chiral/non-centrosymmetric networks; and thus led to a foundation of a new family of functional CPs and MOFs that are reviewed in this invited contribution.
\end{abstract}

Keywords: coordination polymer; metal-organic frameworks; amino acids; transamination 


\section{Introduction}

With its variety of topologies and wide applications, reticular chemistry attained a distinct position in classical coordination chemistry [1-13]. Coordination polymers (CPs) and networks (CNs), metal-organic frameworks (MOFs), organic-inorganic hybrid solids are some of the terminologies extensively encountered in this discipline where dimensionality, nature of interactions, permanent porosity draw a line of demarcation among them. In an archetypical MOF, suitable molecular building blocks of polyatomic inorganic metal-containing clusters and multi-dentate organic linkers could be guided to react in a controlled way and allowed to decode their inherent characteristics or even to express hybrid assets leading to a wide range of geometries and applications [2-5]. 'Permutation and combination' of parameters such as nature of metal ions and pre-designed organic ligands as interacting partners, their molar ratios, solvent medium and experimental conditions (classical or hydrothermal synthesis) can lead to isolation of materials of a wide range of architectures with different levels of nano to meso porosities with a great number of applications. Crafts of organic synthesis to design desired molecular fragments with the advantage of post-synthetic modification leads to diverse CPs/MOFs when integrated with directional properties of different metal ions across the periodic table [6-14].

First generation MOFs due to their permanent porosity, and robustness, were investigated mainly for fuel gas storage, separation, purification, and heterogeneous catalysis. Because of their low density, high surface area and tuneable porosities, such MOFs have emerged as competitors for zeolites, mesoporous materials and carbon nanotubes in the field of storage and separation sciences [2-13]. Among all, particularly interesting are hydrogen storage applications in energy conservative technologies and clean energy. Recent scenario with subsequent generation of MOFs have rationalized with applications extending to technologically relevant domains like non linear optics (NLO) materials [14], spin crossover materials [15-18], porous magnets [12,19-22], and for medical applications [23-25] like drug deliveries, implantable devices, diagnostic sensors, and imaging sensors.

Most of the celebrated MOFs were built from the aromatic carboxylate based secondary building units (SBUs) due to certain positive aspects [2-5]. Combinations with $N$-heterocyclic compounds (imidazole, pyrazole, triazole, tetrazole, etc.) were also conducted because of their various binding and bridging modes [26-33]. Not surprisingly, in a short course, biomolecules and natural products like amino acids [34-46], peptides [47], proteins [46], nucleobases [48], magnesium formates [49], carbohydrates [47], metal glutarates [50,51], $\gamma$-cyclodextrin [36] leaped into this mainstream as attractive precursors and soon tributaries like metal-peptide frameworks (MPFs) [47], metal-biomolecule frameworks (MBioFs) [46-48] surfaced out and established their niche.

Among them the perceptible appearance of amino acid derivatives in recent years, either as metal-based molecular entities or oligomeric scaffolds in MOFs or CPs, justify their inclusion in the synthon/tecton library [34-48]. In this frame, structure and reactivity of different amino acids in their natural or derivatized form were extensively studied. Relevant examples include proline [34,35], glycine [34], valine [36], alanine [37], aspartic acid [38], glutamic acid [36], phenyl alanine [39], histidine [40], methionine [41-44] and typtophan [36-45].

Advantages of amino acids are their natural framework with rich functional groups, which is amenable to derivatization thereby offering intriguing topologies when inserted as building blocks in 
supramolecular hierarchical self-assemblies [34-51]. Indeed, thanks to their genuine chirality (except glycine) and electronic asymmetry, amino acid derivatives are considered as a preeminent choice to introduce asymmetry in MOFs to direct the network construction. Moreover in terms of cost, availability, and bio-compatibility amino acids are considered to be an attractive choice.

Despite these vast reports, comparatively less work has been reported so far on coordination frameworks built from amine derivatized amino acids largely due to the lack of proper functionalization of aminoacids. Keeping potential carboxylic group untouched, derivatization of amine terminal in amino-acids to a moiety that could act as bridging group would be highly desirable in the construction of high dimensional porous network and controlled generation of coordination polymers. In this direction, building a $N$-heterocycle (e.g., 1,2,4-triazole) on the amine terminal in an aminoacid would be a benefit not only in reticular chemistry but also from a synthetic point of view in medicinal chemistry. Advantage of such systems would be the diverse set of coordinating groups on the same ligand backbone: a carboxylic group and a $N$-heterocycle like in histidine.

In this frame, we have recently introduced a simplified transamination reaction for converting the amine functional group of several amino acids into 1,2,4-triazole [52]. We introduced a set of natural and non-natural amino acids selected for their functional group diversity ( $N$-heterocycle, acid, carboxylate, phosphate and thiomethyl) to functionalize into 1,2,4-triazoles (Scheme 1) that could act as potential ligands of $3 \mathrm{~d}$ cations ( $\mathrm{Cu}^{\mathrm{II}}, \mathrm{Fe}^{\mathrm{II}}$ and $\left.\mathrm{Zn}^{\mathrm{II}}\right)$ and $\mathrm{Cd}^{\mathrm{II}}$ [52-55]. In the following section, we shall discuss briefly the synthetic recipe for transamination as well as structural aspects of (a) a trinuclear zinc complex (1) from HL4 [54]; (b) a 1D CP (2) from HL2 and L2, a 2D chiral helicate from HL2 (3) [55]; (c) a 3D Cu-MOF (4) from HL2 [53]. Next, we shall present a section dedicated to various applications of these materials that include (a) the coordinating abilities of these ligands (Scheme 1) $v s$. three zinc- $\beta$-lactamases which is considered as a step towards the design of inhibitors for metallo- $\beta$-lactamases [54] (b) applicability of CP like 3 as suitable sacrificial matrix for generating morphology and phase selective cadmium oxides (c) illustrating with $\mathbf{2}$ and $\mathbf{3}$ advantage of achiral synthon in controlling dimensionality of network and introducing chirality in the network, respectively [55] (d) a 3D porous nanoball $\mathrm{Cu}^{\mathrm{II}} \mathrm{MOF}$ and associated sorption properties and porosity partitioning [53] and (e) $1 \mathrm{D} \mathrm{Fe}^{\mathrm{II}}$ spin crossover $\mathrm{CP}$ with $\mathbf{L 1}$ that act as 'optical alert' at room temperature, which is a highly desirable material in molecular electronics [17].

Scheme 1. 4-R-1,2,4-triazole derived from aminoacids: (L1) Ethyl 4H-1,2,4-triazol-4-ylacetate, (HL2) 4H-1,2,4-triazol-4-yl acetic acid, (L3) Diethyl 4H-1,2,4-triazol-4-yl malonate, (HL4) 4-(methylthio)-2-(4H-1,2,4-triazol-4-yl)Butanoic acid, (L5) Diethyl 4H-1,2,4-triazol-4-yl methylphosphonate.

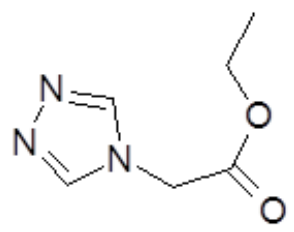

L1

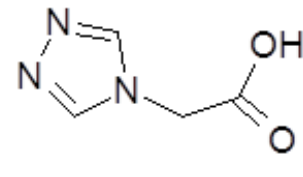

HL2

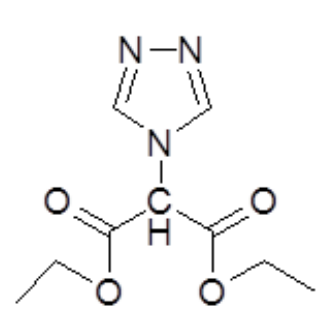

L3

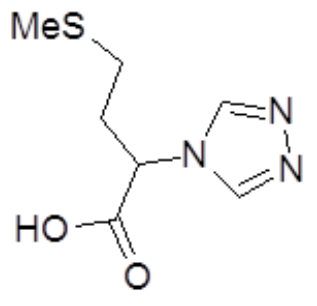

HL4

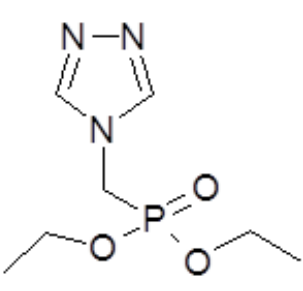

L5 


\section{Functionalization of Amino Acids}

Although the patented Bayer method [58] is routinely employed for 1,2,4-triazole synthesis, 'transamination' was proven to be a more advantageous synthetic strategy to derivatize mainly primary amine into a 1,2,4-triazole. In our earlier report amine exchange process with glycine was successfully carried out in a single step reaction without chromatographic purification to synthesize 4H-1,2,4-triazol-4-yl acetic acid (HL2) [52]. Moderate yield led us to revisit the synthesis and to employ an ester of glycine precursor affording L1 which can be easily hydrolyzed to HL2. This method was extended to tailor other 4R-1,2,4-triazoles from amino-acid and amino-acid esters, namely diethyl aminomalonate (L3), methionine (HL4), diethyl aminomethylphosphonate (L5) and $\beta$-aminoacids, $\beta$-aminoacid ester and $\gamma$-aminoacids [56,57]. Scheme 1 gives an overview of the transformed amino acids via the transamination process.

\section{Structural Aspects}

\subsection{X-Ray Crystal Structure of $\left[\mathrm{Zn}_{3}\left(\mathrm{~L}_{4}\right)_{6}\left(\mathrm{H}_{2} \mathrm{O}\right)_{6}\right]$ (1)}

Reacting HL4 with zinc acetate afforded a white crystalline powder that was recrystallized from hot methanol affording a trinuclear complex $\left[\mathrm{Zn}_{3}(\mathrm{~L} 4)_{6}\left(\mathrm{H}_{2} \mathrm{O}\right)_{6}\right]$ which crystallizes in a trigonal space group (R-3c). In this complex three $\mathrm{Zn}^{\mathrm{II}}$ ions are found in octahedral coordination (Figure 1(a)) with HL4 acting as a $\mu-N 1, N 2$-bridging ligand. Indeed, the central $\mathrm{Zn}^{\mathrm{II}}$ ion is surrounded by six nitrogen atoms belonging to six ligands with $\mathrm{Zn1-N1}=2.159(4) \AA$ and forms a perfect octahedral geometry of $\mathrm{ZnN}_{6}$ $\left(\mathrm{N} 1-\mathrm{Zn} 1-\mathrm{N} 1,180^{\circ}(3)\right)$, while terminal $\mathrm{Zn}^{\mathrm{II}}$ ions are coordinated by three nitrogen atoms (Zn2-N5, 2.145(4) $\AA$ ) from three triazole ligands and three water molecules (Zn2-O14, 2.107(4) $\AA$ ) forming a $\mathrm{ZnN}_{3} \mathrm{O}_{3}$ coordination sphere (with N5-Zn2-O14, 178.4(1) ${ }^{\circ}$ ).

A total of six HL4 ligands bridge in a bidentate fashion to three $\mathrm{Zn}^{\mathrm{II}}$ ions which are equidistant $(\mathrm{Zn} \cdots \mathrm{Zn}=3.848 \AA)$. This distance coincidently matches with that of a known binuclear $\mathrm{Zn}^{\mathrm{II}}$ metalloenzyme from B.cereus (3.848 and $4.365 \AA$ ) (Figure 1(b)) [59] and is typical of trinuclear zinc complexes, e.g., $\left[\mathrm{Zn}_{3}(\text { etrz })_{6}\left(\mathrm{H}_{2} \mathrm{O}\right)_{6}\right]\left(\mathrm{CF}_{3} \mathrm{SO}_{3}\right)_{6}[60]$ with $\mathrm{Zn} \cdots \mathrm{Zn}=3.815(1) \AA$. Across the central $\mathrm{Zn}^{\mathrm{II}}$, on either side, the tripod of 1,2,4-triazole planes adopt a 'staggered' arrangement due to steric requirements and interestingly three aqua ligands on each terminal zinc too adopt the same conformation. The three ligands bridging two $\mathrm{Zn}^{\text {II }}$ ions form a 'paddle wheel' like motif with triazoles planes as propellers. The amine derivatization keeps thioether and carboxylic group to lie on either side of the 1,2,4-triazole plane as pendent arms away from the coordination sphere due to favorable and dominant bridging mode by triazole. These dangling arms are only involved in supramolecular interactions. The torsion angle $\mathrm{C} 10-\mathrm{C} 11-\mathrm{S} 12 \mathrm{~A}-\mathrm{C} 13 \mathrm{~A}$ is $54.8^{\circ}$ which is completely different from that of $\beta$-DL methionine which is $174.9^{\circ}$ [61,62], and all the carbon atoms and sulfur atoms form an almost-planar zigzag chain. But the torsion angle C7-C6-C10-C11 of $173.3^{\circ}$ indicates that main chain carbon atoms lie in a plane away from thiomethyl group. 
Figure 1. (a) Molecular structure of 1 (Adapted from [55] with permission from Elsevier). (b) Enlarged view around zinc coordination sphere in 1 ; $\mathrm{Zn} \cdots \mathrm{Zn}$ matches to that found in binuclear $\mathrm{Zn}$ II metalloenzyme from B.cereus (3.848 A) [54]. (c) Hydrogen bonding (dotted line) network in 1; only hydrogen atoms on coordinated water molecules are shown for clarity. (d) Crystal packing in 1 [54].
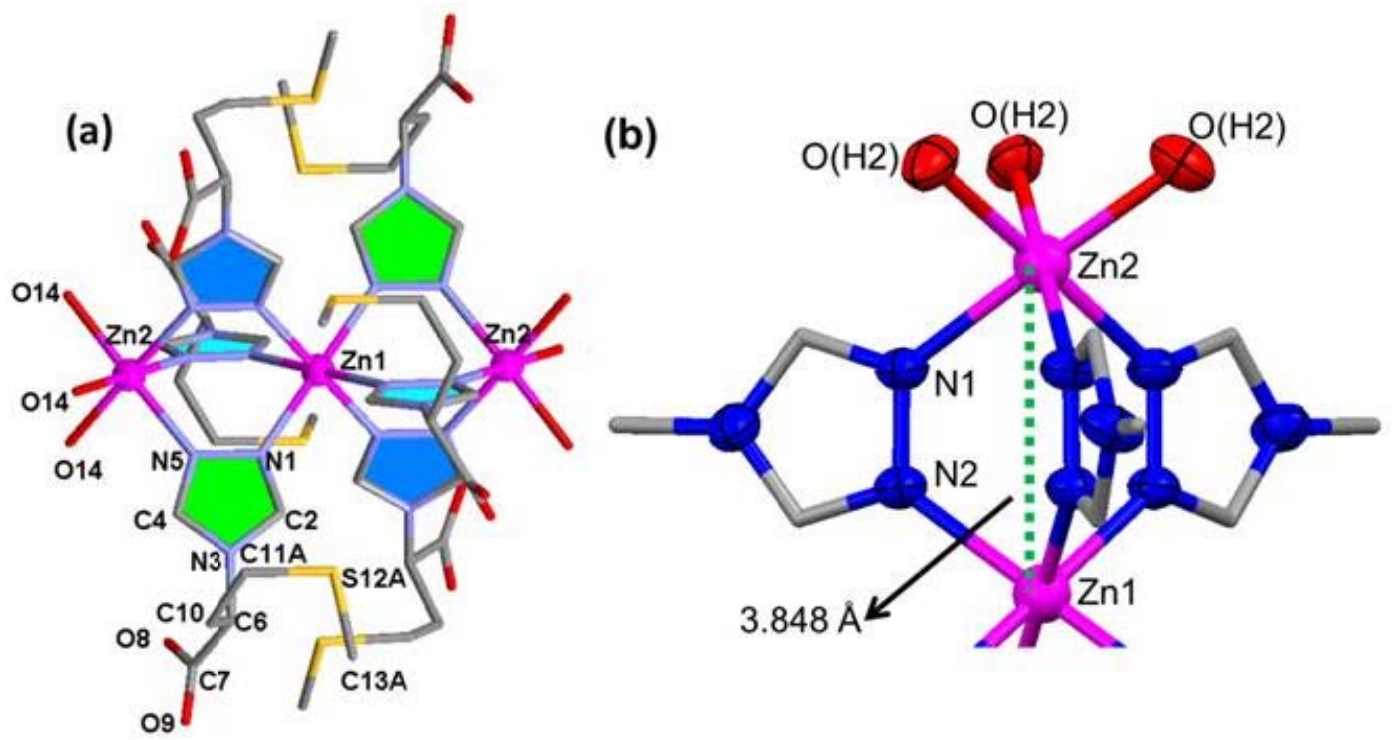

(c)
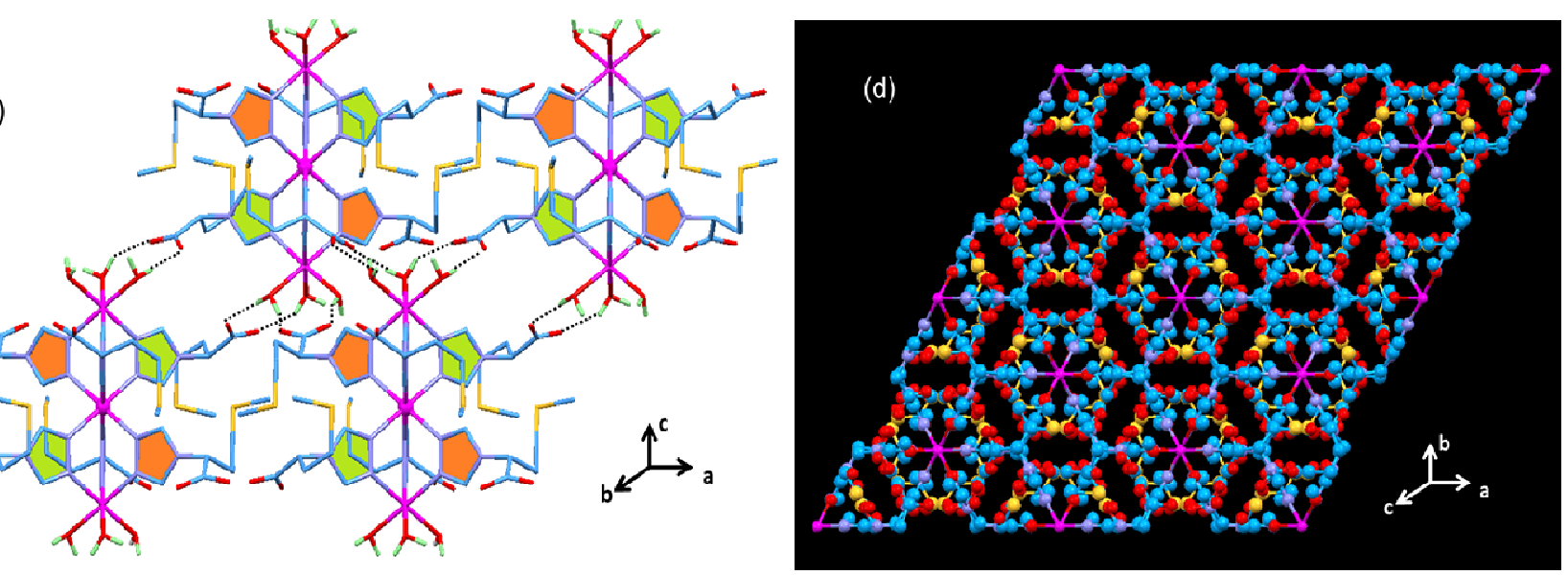

What makes this polynuclear complex distinctive is due to the dual contribution from its ligand. Here HL4 not only acts as a bridging ligand but also as anion due to the presence of deprotonable carboxylic group. Such ionized carboxylate group was reported for a $\mathrm{Pt}^{\mathrm{II}}$ complex where coordination from nitrogen and thiomethyl sulfur is observed thus creating a new sterogenic centre at the sulfur atom [63]. A recent report indicates the use of soft-hard recognition principle in methionine to construct a 3D homochiral coordination network [64]. Choice of $\mathrm{O} / \mathrm{N} / \mathrm{S}$ donor preference for coordination from methionine largely depends on this hard-soft concept over steric encumbrance. In 1 the charge on each metal ion is balanced by the deprotonation of carboxylic group which are engaged in H-bonding. The bond length (C7-O9, 1.223(8) $\AA$; C7-O8, 1.213(8) $\AA$ ) indicates the resonance stabilized double bond after deprotonation. The ethyl(methyl)sulfane group $\left(-\mathrm{CH}_{2}-\mathrm{CH}_{2}-\mathrm{S}-\mathrm{CH}_{3}\right)$ was found to be two-fold disordered. All coordinated water molecules are involved in H-bonding, with oxygen atom of carboxylate group belonging to different molecules [65]. The plane containing chiral 
centre carrying carboxylic moiety tilts $\sim 32^{\circ}$ away from orthogonality with respect to triazole plane,

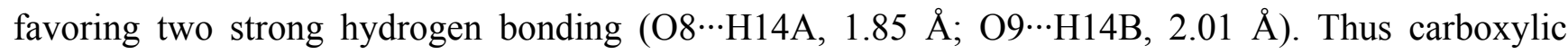
group on each ligand and aqua ligands on terminal zinc act as chain binders establishing the supramolecular interaction (at the periphery) and form a 3D chain (Figure 1(c)). Thus a dense H-bonding network can be seen in this structure. View of crystal packing is shown in Figure 1(d). Recent reports highlight the importance of H-bonding of zinc bound water molecules on catalytic activity [66,67]. It was observed that functional mimics of metallo- $\beta$-lactamases catalytically hydrolyze $\beta$-lactam substrates, such as oxacillin and penicillin G. The high $\beta$-lactamase activity of such compounds was ascribed to the presence of zinc bound water molecules that is activated by being H-bonded to acetate substituent $[66,67]$.

\subsection{X-Ray Crystal Structure of a $1 D \mathrm{CP}$ of $[\mathrm{Cd}(\mathrm{HL} 2 \mathrm{~L} 2) \mathrm{Cl}] \cdot 2 \mathrm{H}_{2} \mathrm{O}$ (2) and of a $2 \mathrm{D}$ Chiral Helicate of} $\left[\mathrm{Cd}_{2}(\mathrm{L2} 2)_{2} \mathrm{Cl}_{2}\right](3)$

Solvothermal and classical synthesis with an identical recipe involving 4H-1,2,4-triazol-4-yl acetic acid (HL2) and $\mathrm{CdCl}_{2}$ afforded rectangular blocks of 1D (2) and hexagonal crystals of 2D (3) CPs, respectively. [Cd(HL2L2)Cl] $2 \mathrm{H}_{2} \mathrm{O}$ (2) crystallizes in the monoclinic space group $P 2_{1} / \mathrm{c}$. Each Cd atom is coordinated by two chloride atoms $(\mathrm{Cd}-\mathrm{Cl}, 2.656(1), 2.616(6) \AA)$, in axial position and four nitrogen atoms $(\mathrm{Cd}-\mathrm{N} 1,2.343(3) \AA, \mathrm{Cd}-\mathrm{N} 2,2.312(3) \AA, \mathrm{Cd}-\mathrm{N} 4,2.374(3) \AA$ and $\mathrm{Cd}-\mathrm{N} 5,2.339(3) \AA)$ belonging to four different ligands forming the equatorial plane, thus completing an octahedral geometry. The triple bridge that is made up of one $\mu$-chloride and two $\mu$-N1,N2-1,2,4-triazole of different L2/HL2 (Figure 2(a)) connect neighboring cadmium centers leading to a 1D coordination polymer with $\mathrm{Cd} \cdots \mathrm{Cd}$ distance of $3.845 \AA$.

Figure 2. (a) Crystal packing depicting a 1D chain in 2 [55]. Adapted with permission from [55]. Copyright 2011 American Chemical Society. (b) View of crystal packing of 2 showing hydrophilic interior (in $a b$ plane) [55].

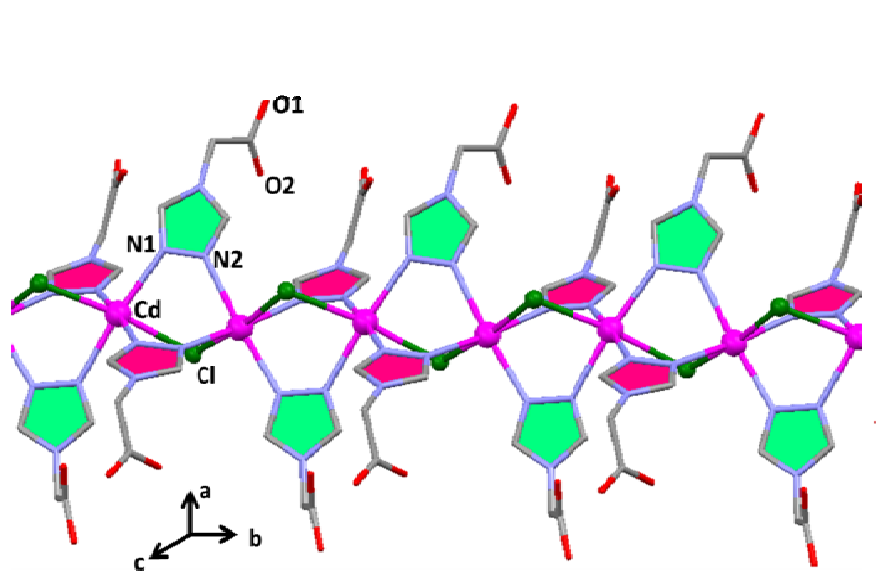

(a)

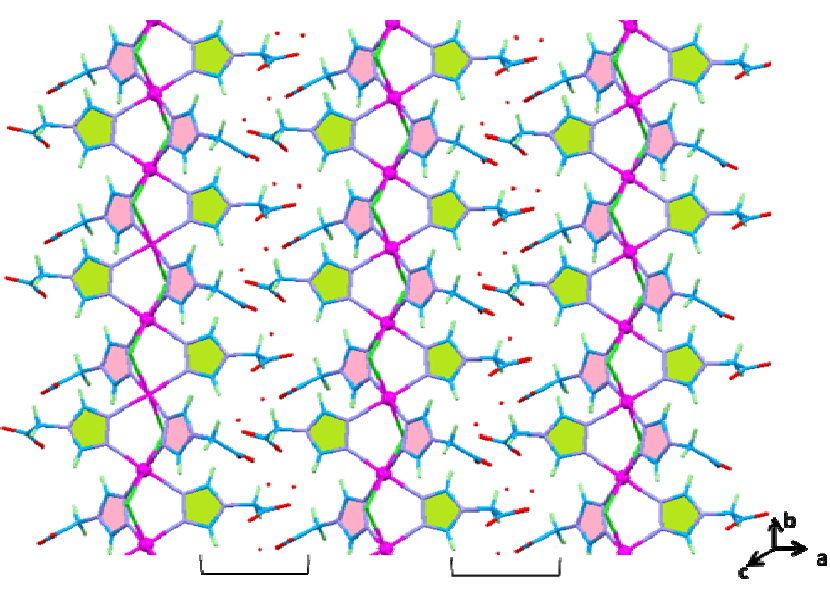

(b)

There are a number of interesting similar Cd MOFs of 1,2,4-triazole derivatives [68]. Lu et al. reported a series of $\mathrm{Cd}$ coordination compounds ranging from 0 to $3 \mathrm{D}$ thanks to substitution of the 1,2,4-triazole or variation of the anion [69]. In a co-ligand modulated Cd-1,2,4-triazolate framework, 
tri and pentacadmium clusters were reported with a slightly longer $\mathrm{Cd} \cdots \mathrm{Cd}$ distance $(4.049 \AA)$ than for 2 [70]. Interesting cases of $\mu-\mathrm{OH}_{2}$ bridged 3,5-disubstituted 1,2,4-triazole systems and polymer chains containing $\mu_{3}-\mathrm{Cl}$ were also reported [71]. It is worth mentioning too, the series of $3 \mathrm{D}$ Cd-triazolate complexes involving anions like $\mathrm{F}^{-}, \mathrm{Cl}^{-}, \mathrm{Br}^{-}, \mathrm{I}^{-}, \mathrm{NO}_{3}{ }^{-}, \mathrm{SO}_{4}{ }^{2-}$ which show diversity in coordination [27]. What makes 2 unique relates to the dual contribution of its ligand system similar to the one described in 1. Indeed, HL2/L2 not only acts as a bridging ligand, but also as anion due to the presence of a deprotonated carboxylate group in HL2. This shows predominance of bridging mode of 1,2,4-triazoles over carboxylic group under present experimental conditions.

The three planes containing ligands are mutually perpendicular around cadmium ions and are threaded by $\mu-\mathrm{Cl}$ anions as intersecting points forming a $1 \mathrm{D}$ zig-zag chain. It was difficult to locate the hydrogen atoms in structure refinement on the carboxylic group of the ligand, but a comparison of bond length of $-\mathrm{C}-\mathrm{O}$ and $-\mathrm{C}=\mathrm{O}$ between ligands contributing to the two planes with that of free HL2 gave evidence of deprotonation. In the free ligand [53], the $-\mathrm{C}=\mathrm{O}$ distance is $1.215(3) \AA$ and the $-\mathrm{C}-\mathrm{O}^{-}$ bond length is $1.307(2) \AA$. It is interesting to note that the ligand exhibiting dual nature forms an exclusively separate plane (Figure 2(a), plane colored in pink) with shortened $\mathrm{C}(4)-\mathrm{O}(1)=1.255(5) \AA$ and $\mathrm{C}(4)-\mathrm{O}(2)=1.251(4) \AA$ distances, which indicates resonance double bond nature as a result of deprotonation. The ligand molecule in the other plane shows bond lengths of $\mathrm{C} 8-\mathrm{O} 3=1.306(4)$ and C8-O4 = 1.206(4) A similar to free ligand. Chloride forms two unequal bonds with cadmium and all the $\mathrm{Cd}-\mathrm{N}$ bond lengths are different as indicated above. Thus the $\mathrm{CdN}_{4} \mathrm{Cl}_{2}$ octahedron is distorted with a distortion parameter of $\Sigma=20.44^{\circ}$ [72]. The tail ends bearing carboxylic groups of the ligands of one plane forming this 1D network face in the same direction. Similarly this region is also shared by a plane from neighboring chain creating a super hydrophilic region (Figure 2(b)). The formation of triple $\mu$-N1,N2-triazole bridging, as found for instance for $\left.[\mathrm{Cu} \text { (hyetrz })_{3}\right]\left(\mathrm{CF}_{3} \mathrm{SO}_{3}\right)_{2} \cdot \mathrm{H}_{2} \mathrm{O}$ [73], or double chloro-bridges plus a single $\mu-N 1, N 2$-triazole bridging [68], was not favored in this network, due to the possibility for the ligand to act as monoanionic. A significant deviation of planes containing the carboxylic group with respect to the triazole planes in $\mathbf{L} 2$ of $\mathbf{2}$, was noted. In HL2, these planes are orthogonal but in 2 they deviate by nearly $21^{\circ}$ (torsion angle (ø), C2-N3-C3-C4, 69.13 ${ }^{\circ}$ ) and $25^{\circ}$ (ø, C5-N6-C7-C8, 65.40 $)$. This deviation is not only due to sterical reasons but also to secondary interactions in the super hydrophilic region. The hydrophilic region is rich in hydrogen bonds, the lattice water molecules being the epicenters of the H-bonding network. Carboxylic groups also greatly contribute to favor a dense H-bonding network. Two H-bonds with the carboxylic groups of different 1,2,4-triazoles from different planes $\left(\mathrm{C} 4-\mathrm{O} 2 \cdots \mathrm{O} 6,2.751 \AA\right.$ with an angle $\mathrm{C} 4-\mathrm{O} 2-\mathrm{O} 6$ of $105.08^{\circ}$ and $\mathrm{C} 8-\mathrm{O} 3 \cdots \mathrm{O} 6,2.568 \AA$ and an angle of $\mathrm{C} 8-\mathrm{O} 3-\mathrm{O} 6$ of $119.25^{\circ}$ ) are found. The deprotonated ligand forms additional $\mathrm{H}$-bonds; one with $2.764 \AA(\mathrm{O} 1 \cdots \mathrm{H}(\mathrm{O} 5))$ with lattice water which in turn forms an $\mathrm{H}$-bond with the chloride bridge $(\mathrm{Cl} \cdots \mathrm{H}(\mathrm{O} 5), 3.228 \AA)$. As a consequence, the bond angle of $122.64^{\circ}$ for $-\mathrm{COO}^{-}$in the free ligand is stretched out to $127.02^{\circ}$ in the complex. The $\mathrm{CH}_{2}$ spacer is also involved in H-bonding with lattice water molecules with $2.628 \AA(\mathrm{C} 3(\mathrm{H} 3 \mathrm{~A}) \cdots \mathrm{O} 1)$. The proton on the triazole ring C6(H6) $\cdots \mathrm{O} 5$ forms a strong H-bond with $2.242 \AA$. Interestingly, the bridging mode of two ligands and one chloride around two $\mathrm{Cd}$ atoms create a bicyclo 7-membered metallomacrocycle ring $[74,75]$.

Hexagonal colorless crystals of $\left[\mathrm{Cd}_{2}\left(\mathrm{~L}_{2}\right)_{2} \mathrm{Cl}_{2}\right]$ (3) crystallize in the non-centrosymmetric orthorhombic space group $P 2{ }_{1} 2_{1} 2_{1}$. The corresponding crystal is shown in Figure 3. 
Figure 3. Molecular structure of 3, showing coordination mode of L2. Homo cis angles, cis- $-\mathrm{CdCl}_{2}$, cis $-\mathrm{CdN}_{2}$ and cis $-\mathrm{CdO}_{2}$ around each $\mathrm{Cd}$ adopt mutually perpendicular conformation [55].

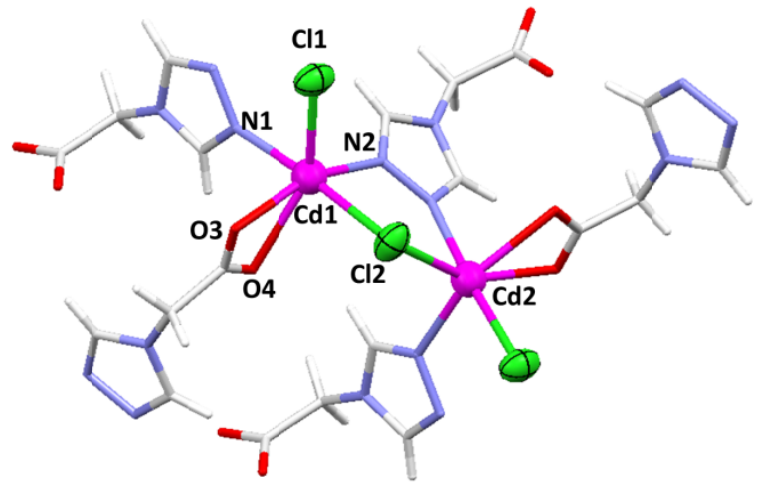

The self-assembling motif consists of two cadmium ions, five ligands and three chloride ions. Although both cadmium ions share the same central core of $\mathrm{CdN}_{2} \mathrm{O}_{2} \mathrm{Cl}_{2}$, they differ in their bond distances and angles. Each $\mathrm{Cd} 1$ atom is coordinated by two bridging $\mathrm{Cl}$ atoms (Cd1-Cl1, 2.543(2) Å; Cd1-C12, 2.598(2) $\AA)$, two L2 molecules via the nitrogen atoms of the ring (Cd1-N1, 2.368(6) $\AA$, Cd1-N2, 2.273(5) $\AA$ ) and one $\mathbf{L} 2$ molecule via both O atoms of the carboxylate group (Cd1-O4,

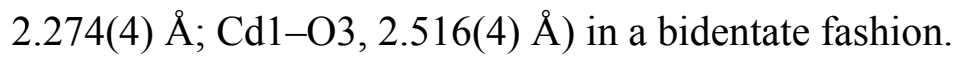

The $\mathrm{Cd} 2$ has a similar environment with slight variation in the $\mathrm{Cd} 2-\mathrm{N}, \mathrm{Cd} 2-\mathrm{O}$ and $\mathrm{Cd} 2-\mathrm{Cl}$ bond distances. The single $\mu-N 1, N 2$-triazole and $\mu$-Cl bridging hold the neighboring cadmium atoms at a distance of $\mathrm{Cd} \cdots \mathrm{Cd}=4.101 \AA$ whereas across the full length of ligand the $\mathrm{Cd} \cdots \mathrm{Cd}$ distance is $8.907 \AA$. This pattern of dissimilar environment around each $\operatorname{Cd} 1(a)$ and $\operatorname{Cd} 2(b)$ propagates in abbaab order along the chain in $c$ direction. The simultaneous use of 1,2,4-triazole and carboxylic groups in coordination with cadmium ions in a self-assembly process thus leads to a $2 \mathrm{D}$ network.

The dihedral angle between 1,2,4-triazole plane and $-\mathrm{CH}_{2} \mathrm{COO}^{-}$planes connected to $\mathrm{Cd} 1$ $(\mathrm{C} 40-\mathrm{N} 5-\mathrm{C} 24-\mathrm{C} 1)$ is $80.72^{\circ}$ whereas across Cd2 (C34-C38-N3-C7) it is $114.0^{\circ}$, which is significantly larger than the value found for the free ligand HL2 [53]. Navigation along the different planes of this structure reveals that this 2D network has a spiral connectivity leading to helicates [76-80]. The propagating chains running along the $a$ axis (Figure 4) are made up of head to tail coordinated L2 molecules connecting $\mathrm{Cd} 1$ atoms to form a helical chain. The resulting intrinsically spontaneous helicity reveals a skeletal structure with a single stranded helix consisting of ligand and cadmium in each turn. Only two cadmium and two ligands span one helical turn so that the helix is considerably compressed. The pitch height of the helix is equal to the length of the crystallographic $a$ axis $(7.579 \AA)$. Helical arrangement implicitly results in chirality producing right $(\Delta=\mathrm{P})$ or left-handed $(\Lambda=M)$ helicity around principal axes [76-80]. The cylindrical helices are arranged in an alternating right-handed and left-handed fashion in the intrachain ' $a$ ' direction with a distance of $10.3 \AA$ (Figure 4) which are domains of opposite helicity. Thus the complex is racemic because the right and left handed chains are alternatively arranged but in $b$ direction, it shows single handedness. The helical twist of the strand results from the torsion between the 1,2,4-triazole plane and the spacer connecting the chelating carboxylic group. The orientation of the $-\mathrm{CH}_{2}$ [81] (winged, $(w)$ or pinched, $(p)$ ) is crucial to direct the spirality. Both the $-\mathrm{CH}_{2}$ of each turn adopt a favorable winged orientation. This spiral 'staircase' leaves 
behind a roughly polygonal cavity of $4.89 \AA(\mathrm{O} 3-\mathrm{O} 3) \times 6.224 \AA(\mathrm{C} 24-\mathrm{C} 24)$. Helicity has previously been noticed on a few 1,2,4-triazole CPs. In a related system constructed from of 3-amino-1,2,4triazolate, where additionally cadmium ions are bridged by bromide ions, two kinds of helical channels with opposite chirality were observed [74]. With 3-amino-1,2,4-triazole, a Cd ${ }^{\mathrm{II}}$ coordination framework with a 2D helical channel was also recently reported [75].

Figure 4. (a) Crystal packing in 3 illustrating chirality; (b) View of a spiral staircase [55]. Adapted with permission from [55]. Copyright 2011 American Chemical Society.
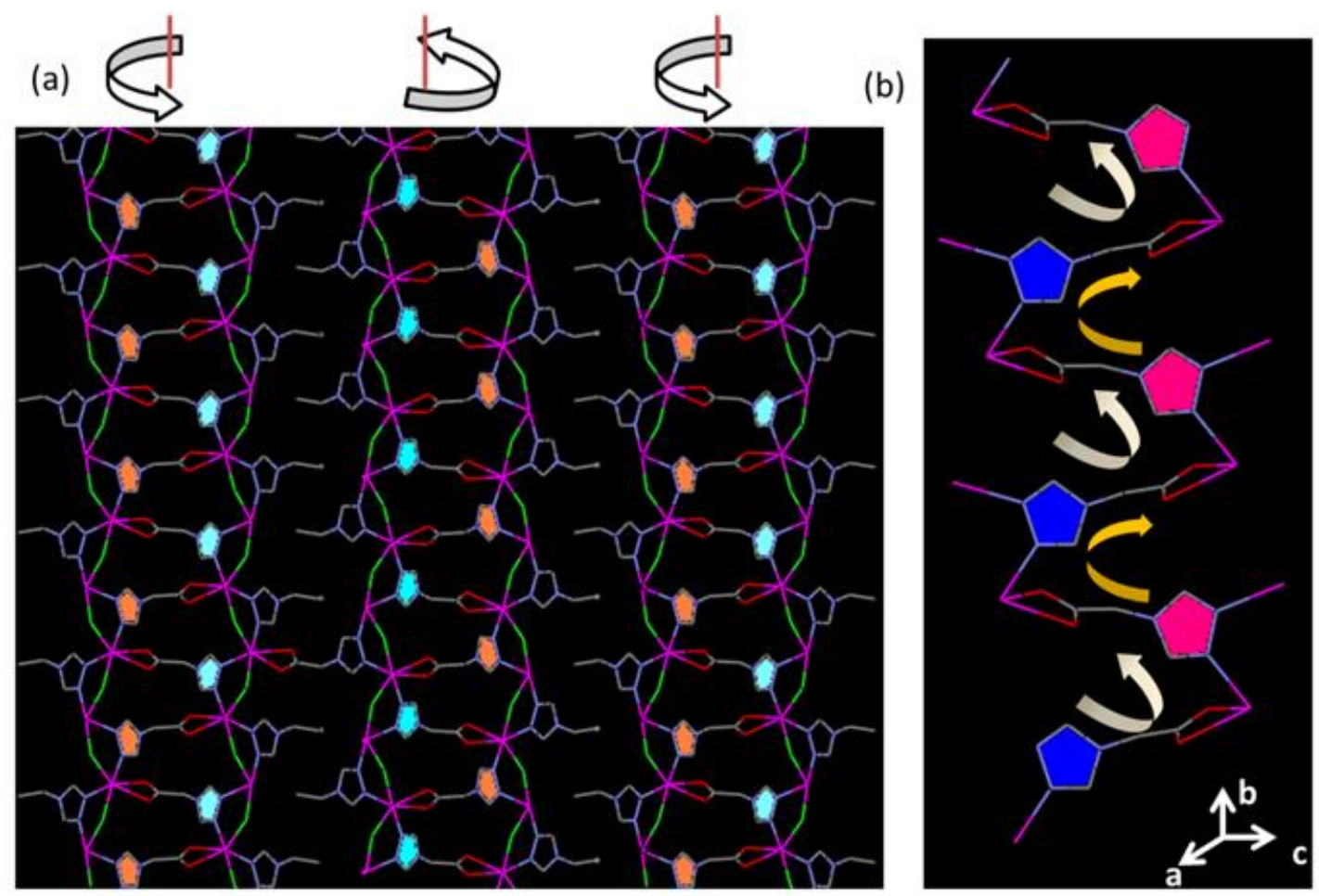

\subsection{X-Ray Crystal Structure of $\left[\mathrm{Cu}_{3}\left(\mu_{3}-\mathrm{O}\right)(\mathrm{HL2})_{6} \cdot\left(\mathrm{H}_{2} \mathrm{O}\right)_{3}\right] \mathrm{BF}_{4} \cdot \mathrm{H}_{2} \mathrm{O}$ (4)}

Reaction of $\mathbf{H L 2}$ with aq $\mathrm{Cu}\left(\mathrm{BF}_{4}\right)_{2}$ in water afforded $\left[\mathrm{Cu}_{3}\left(\mu_{3}-\mathrm{O}\right)(\mathrm{HL} 2)_{6} \cdot\left(\mathrm{H}_{2} \mathrm{O}\right)_{3}\right] \mathrm{BF}_{4} \cdot \mathrm{H}_{2} \mathrm{O}$, (4) in low yield. The yield can be dramatically improved when HL2 was replaced by L1 and slowly hydrolyzing the ester functionality by a base. The dark blue cubic crystals thus obtained crystallize in a cubic space group (I $\overline{4} 3 \mathrm{~m}$ ). Mixed coordination environments of $\mathrm{N}$ and $\mathrm{O}$ are seen around copper. Three copper atoms are lodged at the vertices of an equilateral triangle around $\mu_{3}-\mathrm{O}$ keeping $\mathrm{Cu} \cdots \mathrm{Cu}$ distance of $3.368 \AA$ (Figure 5(a)). This value compares well with a similar triangular tricopper MOF built from unsubstituted 1,2,4-triazole $(\mathrm{Cu} \cdots \mathrm{Cu}=3.439 \AA)$ [82]. An overview of the crystallographic parameters of 1-4 is given in Table 1 for further comparison. The copper centre is in ' $4+1$ ' $\left(\mathrm{CuN}_{2} \mathrm{O}_{3}\right)$ square pyramidal geometry and each copper binds three ligands: two ligands coordinate through nitrogen of 1,2,4-triazole in a $N_{l}, N_{2}$ bridging mode $(\mathrm{Cu}-\mathrm{N} 2=1.950(9) \AA)$ while one ligand coordinates through a carboxylate group in an unidentate fashion $(\mathrm{Cu}-\mathrm{O} 9=1.943(1) \AA)$ and a water molecule loosely coordinated to copper (2.32(2) $\AA$ ). The Addison structural index parameter $\tau$, which is relevant for five-coordinate structures as an index of the degree of trigonality [83], was evaluated as 0.014 thus confirming a square pyramidal geometry. This triangular, tricopper(II) unit supported by $-\mu_{3}-\mathrm{O}$ bridging and six ligands, forms the secondary building unit (SBU). The $\mu_{3}-\mathrm{O}$ atom is in nearly 
planar triangular coordination sphere with an average $\mathrm{Cu} \cdots \mu_{3}-\mathrm{O}$ distance of $1.946(2) \AA$. The $\mathrm{Cu}-\mathrm{O}-\mathrm{Cu}$ angle is of nearly $120^{\circ}\left(119.8(1)^{\circ}\right)$ which is indicative of a $\mathrm{sp}^{2}$ configuration of oxygen atom [82]. This SBB has a three-fold axis of symmetry passing through $\mu_{3}-\mathrm{O}$.

Figure 5. (a) View of triangular tricopper $\mu_{3}$-oxo bridged secondary building units (SBU) in 4 [54]. (b) View of self-assembly of the SBU architecturing a nanoball type cavity in 4 [53].

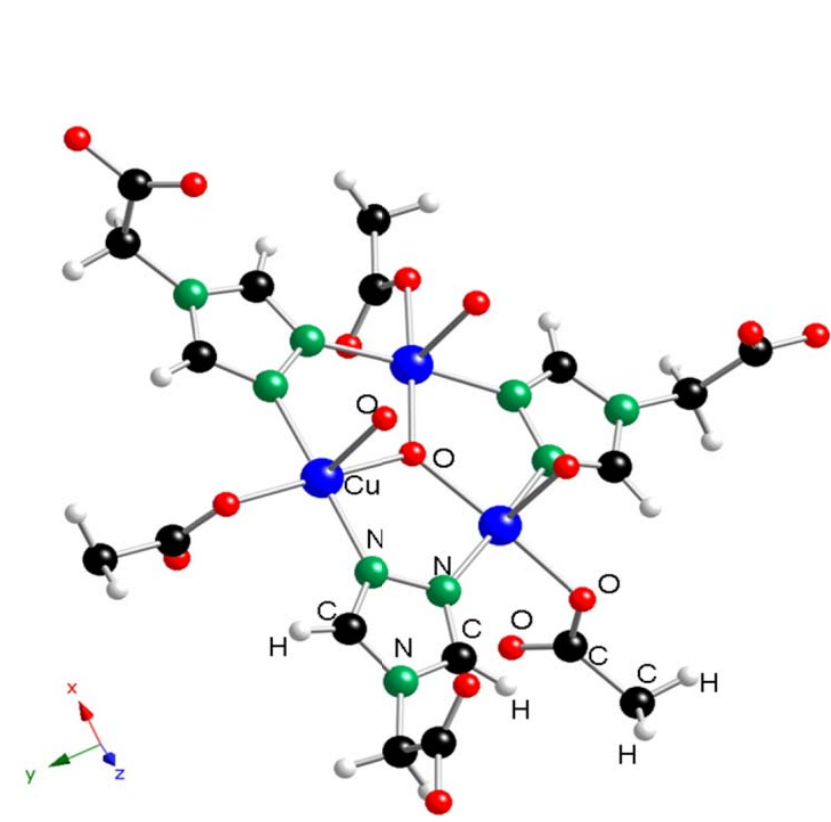

(a)

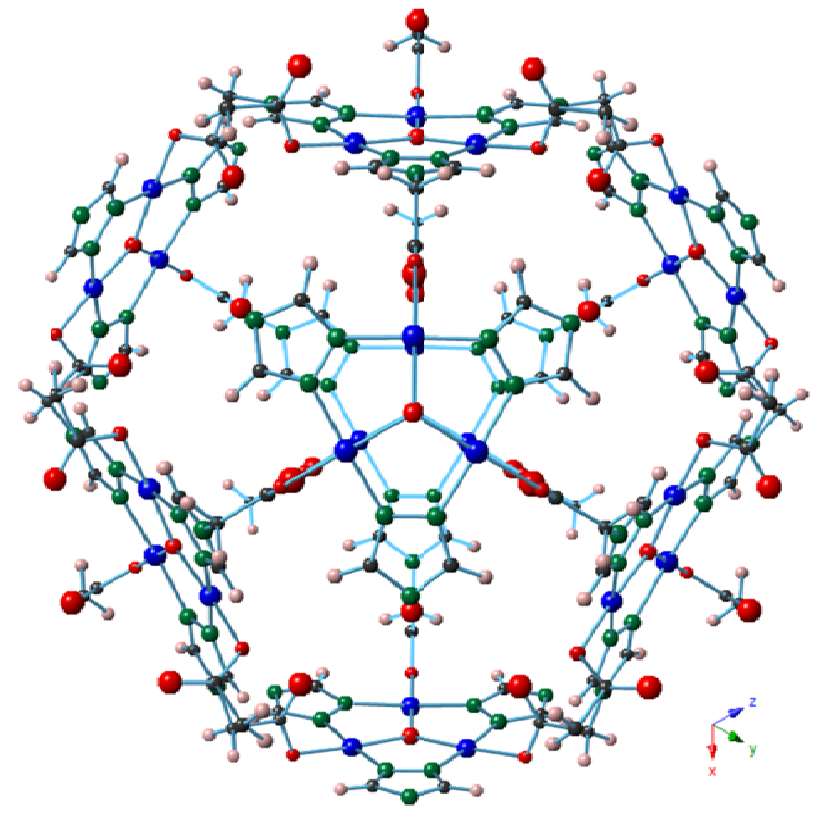

(b)

Table 1. Comparison of crystallographic parameters among related compounds.

\begin{tabular}{|c|c|c|c|c|c|c|}
\hline Code & $\begin{array}{c}\text { Space Group (type) } \\
\text { T (K) }\end{array}$ & $\begin{array}{c}\text { Torsion angle } \\
\left({ }^{\circ}\right)\end{array}$ & $\begin{aligned}-\mathrm{C}= & \mathrm{O},-\mathrm{C}-\mathrm{O} \text { distance } \\
& (\AA) / \text { Mode of } \\
& \text { coordination }\end{aligned}$ & $\begin{array}{c}\text { M...M } \\
\text { Distance } \\
(\AA)\end{array}$ & $\begin{array}{c}\text { Network (Coordination } \\
\text { sphere) }\end{array}$ & Ref. \\
\hline HL2 & $\begin{array}{l}\text { non-centrosymmetric } \\
\text { orthorhombic }(F d d 2) \text {; } \\
120(2)\end{array}$ & $\begin{array}{l}\mathrm{C} 5-\mathrm{N} 4-\mathrm{C} 6-\mathrm{C} 7 \\
=80.69\end{array}$ & $\begin{array}{l}(-\mathrm{C}=\mathrm{O})=1.215(3) \\
-\mathrm{C}-\mathrm{O}=1.307(2)\end{array}$ & . & $\begin{array}{l}\text { Supramolecular 2D } \\
\text { network }\end{array}$ & [53] \\
\hline 1 & $\begin{array}{l}\text { centrosymmetric } \\
\text { rhombohedric, } \\
(R-3 \mathrm{c}) ; 120(2)\end{array}$ & $\begin{array}{l}\text { C5-N4-C6-C7 } \\
=121.76\end{array}$ & $\begin{array}{l}\mathrm{C} 7-\mathrm{O} 8=1.213(8) \\
\mathrm{C} 7-\mathrm{O} 9=1.223(8) \\
\text { /not involved }\end{array}$ & 3.848 & $\begin{array}{l}\text { Trinuclear complex, } \\
\mathrm{ZnN}_{6} \text { and } \mathrm{ZnN}_{3} \mathrm{O}_{3}\end{array}$ & [54] \\
\hline 2 & $\begin{array}{l}\text { centrosymmetric } \\
\text { monoclinic }\left(P 2_{1} / \mathrm{c}\right) \\
293(2)\end{array}$ & $\begin{array}{l}\text { C5-N6-C7-C8 } \\
=66.4 \\
\mathrm{C} 1-\mathrm{N} 3-\mathrm{C} 3-\mathrm{C} 4 \\
=109.96\end{array}$ & $\begin{array}{l}\mathrm{C} 4-\mathrm{O} 2=1.251(4) \\
\mathrm{C} 4-\mathrm{O} 1=1.255(5) \\
\mathrm{C} 8-\mathrm{O} 4=1.206(4) \\
\mathrm{C} 8-\mathrm{O} 3=1.306(4) \\
\text { /not involved }\end{array}$ & 3.845 & $\begin{array}{l}\text { 1D coordination } \\
\text { polymer } \mathrm{CdN}_{4} \mathrm{Cl}_{2}\end{array}$ & [55] \\
\hline 3 & $\begin{array}{l}\text { non-centrosymmetric } \\
\text { orthorhombic }\left(P 2_{1} 2_{1} 2_{1}\right) \\
293(2)\end{array}$ & $\begin{array}{l}\text { C40-N5-C24-C1 } \\
=80.72 \\
\text { C7-N3-C38-C34 } \\
=114\end{array}$ & $\begin{array}{l}\mathrm{C} 34-\mathrm{O} 1=1.257(8) \\
\mathrm{C} 34-\mathrm{O} 2=1.229(8) \\
\mathrm{C} 1-\mathrm{O} 4=1.261(8) \\
\mathrm{C} 1-\mathrm{O} 3=1.235(8) \\
\text { /bidentate }\end{array}$ & 4.101 & $\begin{array}{l}\text { Supramolecular 2D } \\
\text { network (helical); } \\
\mathrm{CdCl}_{2} \mathrm{~N}_{2} \mathrm{O}_{2}\end{array}$ & [55] \\
\hline 4 & $\begin{array}{l}\text { non-centrosymmetric } \\
\text { cubic }(I \overline{4} 3 \mathrm{~m}) ; 120(2)\end{array}$ & $\begin{array}{l}\text { N3-N4-C6-C7 } \\
=87.37\end{array}$ & $\begin{array}{l}\mathrm{C} 7-\mathrm{O} 8=1.19(2) \\
\mathrm{C} 7-\mathrm{O} 9=1.29(2) \\
\text { /monodentate }\end{array}$ & 3.368 & $\begin{array}{l}3 \mathrm{D} \text { chains of nanoballs, } \\
\mathrm{CuN}_{2} \mathrm{O}_{3}\end{array}$ & [53] \\
\hline
\end{tabular}


The self assembly of this rigid SBU in 3D generates a cage like structure. The interlinking arrangement of eight such SBUs generates a molecular cage/porous ball which can be considered as tertiary building unit (TBU) or 'supercluster' [84,85]. The axially bound 24 water molecules on each of 24 copper atoms of TBU cage, decorate a hydrophilic interior pointing towards the void. The total solvent accessible volume is $4,477.5 \AA^{3}$ which accounts for $48 \%$ of the cell volume. The distance between opposite oxo-centers is 18.219 A. Considering van der Waals radii, the void may admit a sphere of $1 \mathrm{~nm}$ of diameter (Figure 5(b)). Each nanoball is the artifact of 96 molecules $\left(24 \mathrm{Cu}^{2+}\right.$ ions, 24 water molecules, and 48 ligands) self-assembling in three dimensions (Figure 6). Each nanoball is tunneled into six neighboring nanoballs through a roughly square window/aperture. These mutually perpendicular $3 \mathrm{D}$ channels represent a kind of undulating passages.

Figure 6. View of chains of porous nanoballs in 4 [53].

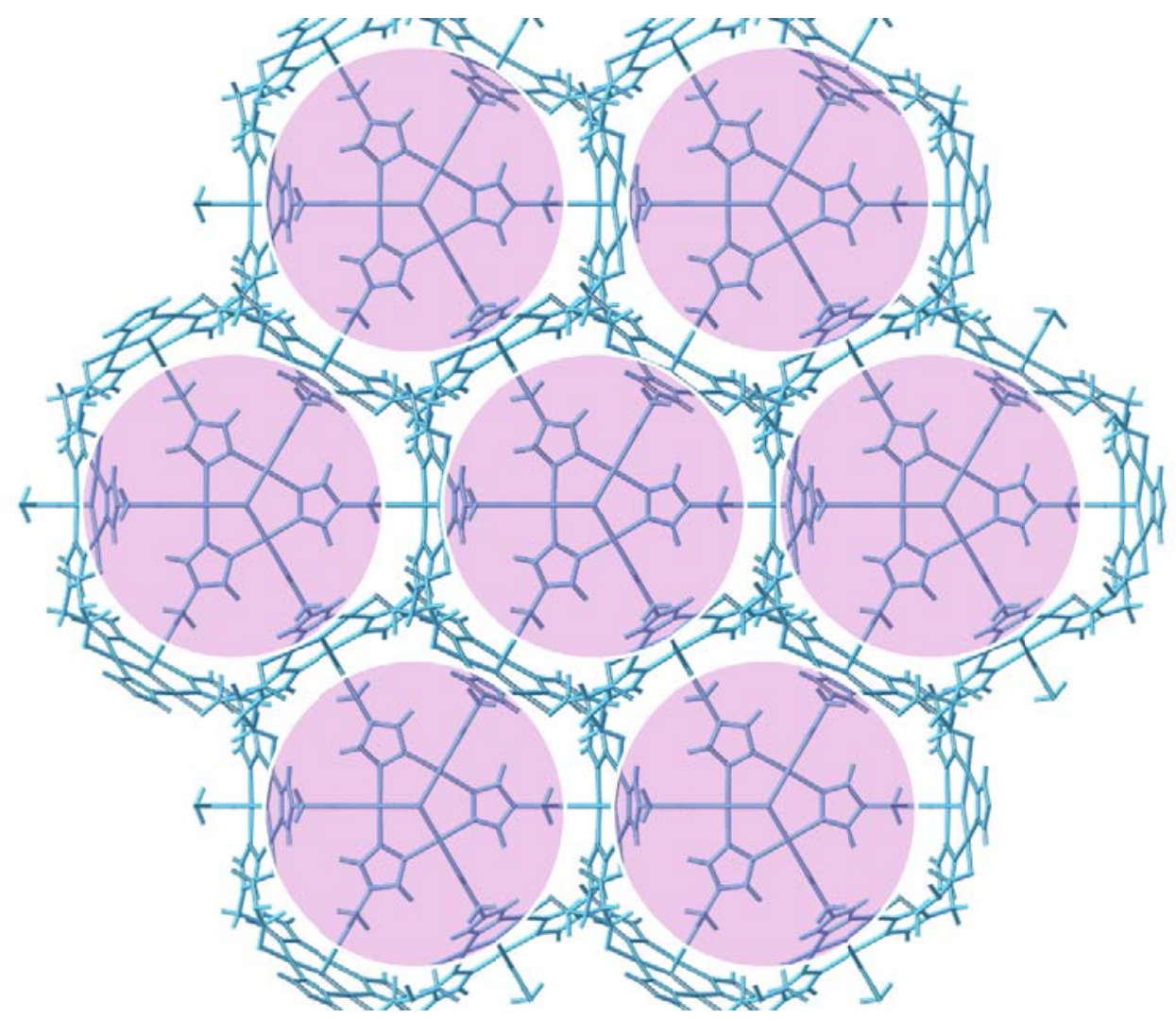

Since each TBU is roughly spherical, their specific spatial arrangement in 3D obviously generates smaller voids/interstices as can be seen in the body centered cubic arrangement of spheres. The larger channels open into smaller hydrophobic ones which are roughly square shaped $(6.328 \times 6.328 \AA)$ and where the non coordinated $\mathrm{BF}_{4}{ }^{-}$anions are stranded. Indeed, anions are distributed in both periphery of hydrophilic and centre of hydrophobic channels. Water molecules of crystallization are lying within the cavity anchored by $\mathrm{H}$-bonding. The $-\mathrm{C}=\mathrm{O}$ of carboxylic group with a length of $1.215(3) \AA$ in free ligand is lowered to $1.187(2) \AA$ in the complex due to H-bonding with the water molecules, whereas the $\mathrm{C}-\mathrm{O}$ length in the ligand is lowered by approximately $0.06 \AA$ to $1.294(1) \AA$, upon coordination to copper. 
The semi-rigid nature of the ligand framework was realized after closely studying the bond length and torsion angle changes upon complexation. The crooked ligand with an obtuse angle of $110.6(2)^{\circ}$ between $\mathrm{N} 4-\mathrm{C} 6-\mathrm{C} 7$ has flexed out to $112.0(1)^{\circ}$, while that of $\mathrm{C} 6-\mathrm{C} 7-\mathrm{O} 8$ with $115.5(2)^{\circ}$ bent to $122.2(1)^{\circ}$ in 4 . The dihedral angle between two planes involving N4-C6-C7-O9 in 4 is exactly $180^{\circ}$ which means that the two planes are stiffened to lie parallel as opposed to an angle of $176(1)^{\circ}$ in the ligand. The flexibility is also evident from the change in dihedral angle between triazole plane and plane containing $-\mathrm{CH}_{2}-\mathrm{O}$ group from $81^{\circ}(1)$ in $\mathbf{H L 2}$ to $87^{\circ}$ in 4 . These parameters may assist in redesigning the framework for specific applications like gas storage where a spacer length and bent angle as well as pore volume could be tuned.

\section{Selected Applications}

Applications envisioned in majority of the coordination chemistry of derivatized amino acids are largely dependent on the molecular conformations the precursors adopt during the self-assembly process in their MOF as their conformation controls structure-function relationship. Some examples are discussed below.

\subsection{Biological Applications: $\beta$-Lactamase Assay of Selected 1,2,4-Triazole Aminoacids}

The coordinating abilities of $\mathbf{L 1}-\mathbf{L 5}$ (Scheme 1) with $\mathrm{Zn}^{\mathrm{II}}$ ions in solution, solid state and $v s$. three zinc- $\beta$-lactamases have been exploited through inhibition assays. The production of $\beta$-lactamases is the most common mechanism of bacterial resistance to $\beta$-lactam antibiotics, i.e., penicillins, cephalosporins, and carbapenems [86]. These defense enzymes pose serious medical problems, mainly in hospital environments because they rapidly hydrolyze drugs thus reducing curing efficiency. Most of $\beta$-lactamases are serine-proteases (classes A, C and D) against which selective $\beta$-lactam inhibitors, such as tazobactam, have been developed and marketed for coadministration with antibiotics [87]. Metallo- $\beta$-lactamases (i.e., zinc proteases) constitute the class B [86]; presently, none of the inhibitors of zinc- $\beta$-lactamases have emerged for therapeutical use. Thus the search for non- $\beta$-lactam compounds, susceptible to form $\mathrm{Zn}^{\mathrm{II}}$ complexes, could be a valuable strategy to discover inhibitors of class B $\beta$-lactamases [88]. L1-L5 were screened for inhibition against three representative metallo- $\beta$-lactamases, namely BcII from Bacillus cereus [89], CphA from Aeromonas hydrophila [90] and L1 from Stenotrophomoncas maltophilia [91] representing B1, B2 and B3 sub-classes. CephA exists mainly in the mono-zinc form, while L1 forms a dinuclear active site [92]; the question of one or two $\mathrm{Zn}^{\mathrm{II}}$ ions in the class of BcII is still open [93]. The tested compounds were pre-incubated with the enzymes $\left(30 \mathrm{~min} 30^{\circ} \mathrm{C}\right.$ ) before addition of imipenem antibiotic. The enzymatic residual activity was determined by monitoring the drug hydrolysis at $300 \mathrm{~nm}$ using a spectrophotometer. Although this assay clearly indicates that tested ligands are very weak inhibitors of class B $\beta$-lactamases, one compound (HL4) can be retained as a modest inhibitor of BcII enzyme. As a matter of fact, the HL4 ligand is able to form a polynuclear $\mathrm{Zn}^{\mathrm{II}}$ complex, as shown by the X-ray crystal structure (Section 3.1). The BcII inhibition may result from the complexation of one or two zinc ions of the active site by 4-(methylthio)-2-(4H-1,2,4-triazole-4-yl)butanoic acid molecules which could stimulate further developments in medicinal chemistry [54]. 


\subsection{Coordination Polymers as 'Soft' Sacrificial Matrix for Morphology and Phase Selective CdO}

Production by Controlled Pyrolysis of $\left[\mathrm{Cd}_{2}\left(\mathrm{~L}_{2}\right)_{2} \mathrm{Cl}_{2}\right]$ (3)

In material sciences, metal threaded "soft" nonaromatic networks like $\mathbf{3}$ give tangible perception for facile generation of oxide material upon controlled breakdown of their network. Such methods where surface energy and growth kinetics can be fine tuned offer tailoring architecture of nano- and microcrystals oxide. Various synthetic methods were explored to prepare cadmium oxides owing to their shape- and size-dependent technological applications such as photovoltaic cells, gas sensors, transparent conductive oxides, phototransistors, photodiodes, transparent electrodes, in the form of rods and wires [94], whiskers [95], disk [96], cubes, belts [97,98], most of which are based on physical and chemical technique such as sol-gel, spray pyrolysis, sputtering method, Langmuir-Blodgett deposition, solvothermal synthesis, and controlled decomposition of MOF [98,99]. Thermogravimetric analyses (TGA) of 1 (Figure 7(a)) provides an overview of thermal stability and decomposition patterns. After the initial weight loss around $45{ }^{\circ} \mathrm{C}$, which is due to surface moisture, the compound was stable until $170{ }^{\circ} \mathrm{C}$ and then decomposed into three ill-defined broad steps from 200 to $900{ }^{\circ} \mathrm{C}$. At $850{ }^{\circ} \mathrm{C}$ a complete destruction of the ligand framework is evidenced. In a typical pyrolysis procedure, 3 was heated at a rate of $10{ }^{\circ} \mathrm{C} / \mathrm{min}$ until $850{ }^{\circ} \mathrm{C}$ and allowed to rapidly cool to r.t., which led to isolation of a white residue. Scanning electron microscopy (SEM) images (Figure 7(b)) on this residue showed the presence of nearly cubic rods with thickness of $800 \mathrm{~nm}$. The poor quality of the powder X-ray diffraction (PXRD) pattern did not allow us to assign it to any known phase. As mild sputtering was frequently observed with this procedure, the isolation of sufficient quantity of residue was difficult. This led us to use a mild thermal treatment of $1{ }^{\circ} \mathrm{C} / \mathrm{min}$ until $850{ }^{\circ} \mathrm{C}$ instead, followed by rapid cooling to r.t. The obtained reddish-brown residue was considered for further investigation for phase identification, purity, and morphological characterization.

The PXRD pattern shown in Figure 7(f) was indexed to the powder pattern of the pure cubic phase of CdO ( $\beta$-form) (JCPDS file No. 05-0640) [100,101]. The diffractogram shows prominent peaks at $2 \theta\left(^{\circ}\right)=32.99,38.29,55.27,65.94,69.26$, which are associated with (111), (200), (220), (311) and (222) planes, respectively. It clearly shows that $\mathrm{CdO}$ crystallizes in rock-salt cubic structure. The pattern does not reveal any other peaks thereby confirming excellent phase purity. SEM images of this oxide (Figure 7(c)) shows truncated octahedron shaped crystals of 1-2 $\mu \mathrm{m}$ size. The shaping of these oxides can be further tuned and the same results of phase purity (based on XRPD pattern) were observed for the reddish brown residue obtained when pyrolysis was extended up to 850 or $900{ }^{\circ} \mathrm{C}$, and subsequently allowed to be slowly cooled to r.t. In the former case, hexagonal blocks were obtained (Figure 7(d)), whereas a treatment at $900{ }^{\circ} \mathrm{C}$ afforded well-defined octahedral crystals (Figure 7(e)), both of them in the range of 1-2 $\mu \mathrm{m}$. This demonstrates that such 'soft' non-aromatic CPs could be a suitable host to carve desired metal oxide with control over morphology and phase selectivity [55]. 
Figure 7. (a) TGA pattern of 3, (b-e) Morphology of CdO crystals obtained at different conditions of pyrolysis: (b) rectangle blocks (white residue of $\mathrm{CdO}$ ) (c) truncated octahedra (d) hexagonal blocks (e) octahedron (f) PXRD of red form of CdO ( $\beta$-form) [55]. Adapted with permission from [55]. Copyright 2011 American Chemical Society.
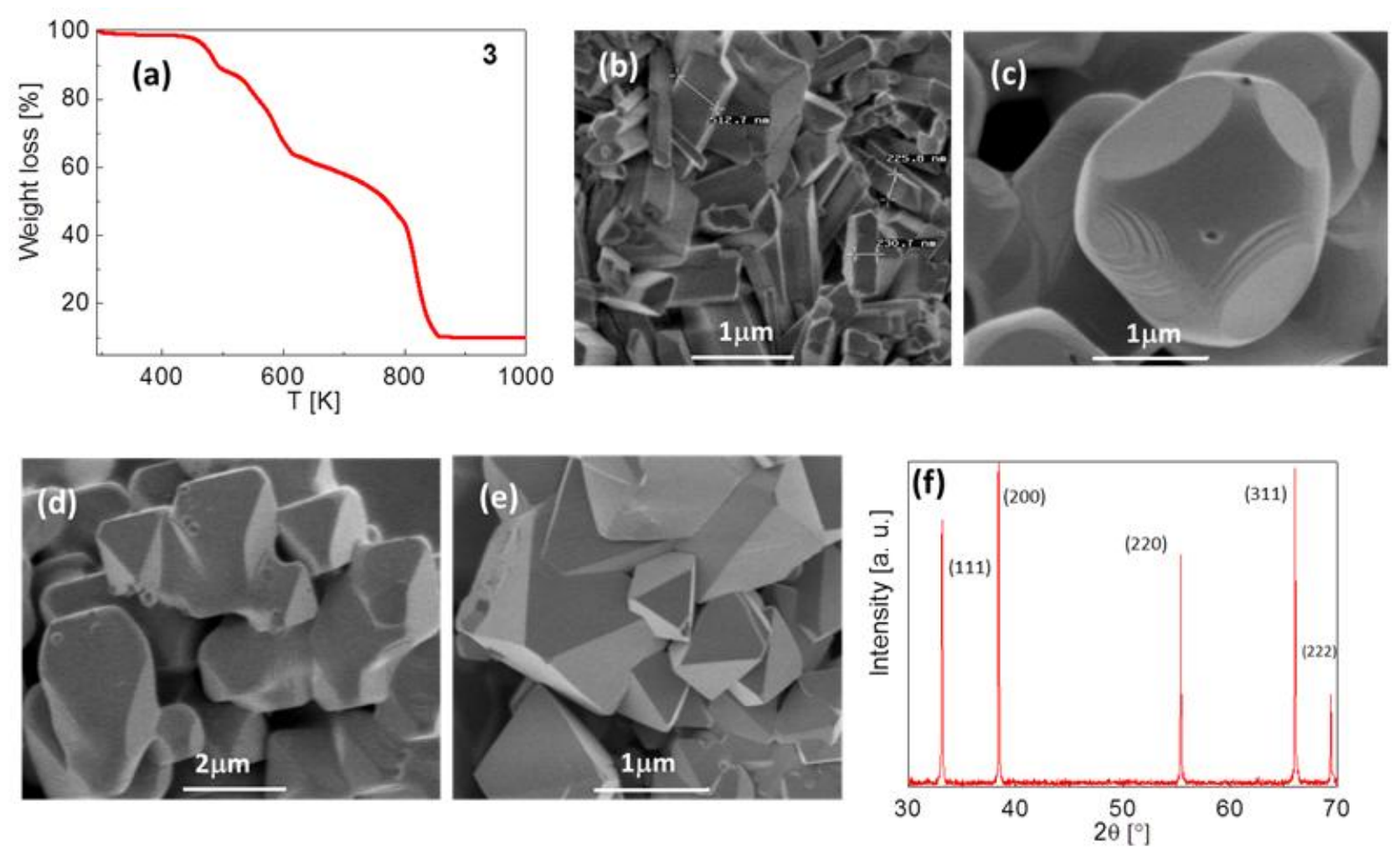

\subsection{Sorption Studies and Porosity Partitioning Studies in 3D MOF}

The nanoporous void found in $\mathbf{4}$ prompted us to investigate gas adsorption capacity and to study the porosity partitioning by mercury porosimetry. A gas sorption study for $\mathbf{4}$ was carried out using $\mathrm{N}_{2(\mathrm{~g})}$ and $\mathrm{H}_{2(\mathrm{~g})}$. Before measurements, the crystalline sample was vacuumed either with a gradual increase of temperature or rapid heating until $150{ }^{\circ} \mathrm{C}$, the temperature corresponding to the end of dehydration according to TGA analysis. Within the relative pressure range investigated, the $\mathrm{N}_{2(\mathrm{~g})}$ adsorption measurements did not show any gas uptake, thus making impossible the determination of the specific surface area by routine BET (Brunauer, Emmett, Teller) calculation. An adsorption was however observed for $\mathrm{H}_{2(\mathrm{~g})}$. This adsorption difference between these two molecules could be related to their size, their kinetic diameter being $2.8 \AA\left(\mathrm{H}_{2(\mathrm{~g})}\right)$ and $3.6 \AA\left(\mathrm{N}_{2(\mathrm{~g})}\right)$ [102]. The $\mathrm{H}_{2(\mathrm{~g})}$ adsorption of $1.8 \mathrm{~cm}^{3} / \mathrm{g}$ and $2.7 \mathrm{~cm}^{3} / \mathrm{g}$ for the fast and slow out-gassing, respectively, is irreversible, which was confirmed by several consecutive runs. These low values could account for little surface adsorption as observed for a related SBU system [29]. These poor adsorption properties could also result from the breakdown of the network after thermal pre-treatment. This prompted us to revisit the gas adsorption measurement with mild pre-treatment at ambient condition. The fresh crystals were evacuated overnight under vacuum without any warming treatment. 
Figure 8. (a) Adsorption and desorption isotherms for 4 at $77 \mathrm{~K}$ of $\mathrm{H}_{2(\mathrm{~g})}$ degassed at room temperature. (b) Intrusion curve as observed by $\mathrm{Hg}$ porosimetry; inset shows SEM micrograph of single crystal of $\mathbf{4}$ showing square shaped pores on the surface [53]. Adapted with permission from [53]. Copyright 2010 American Chemical Society.
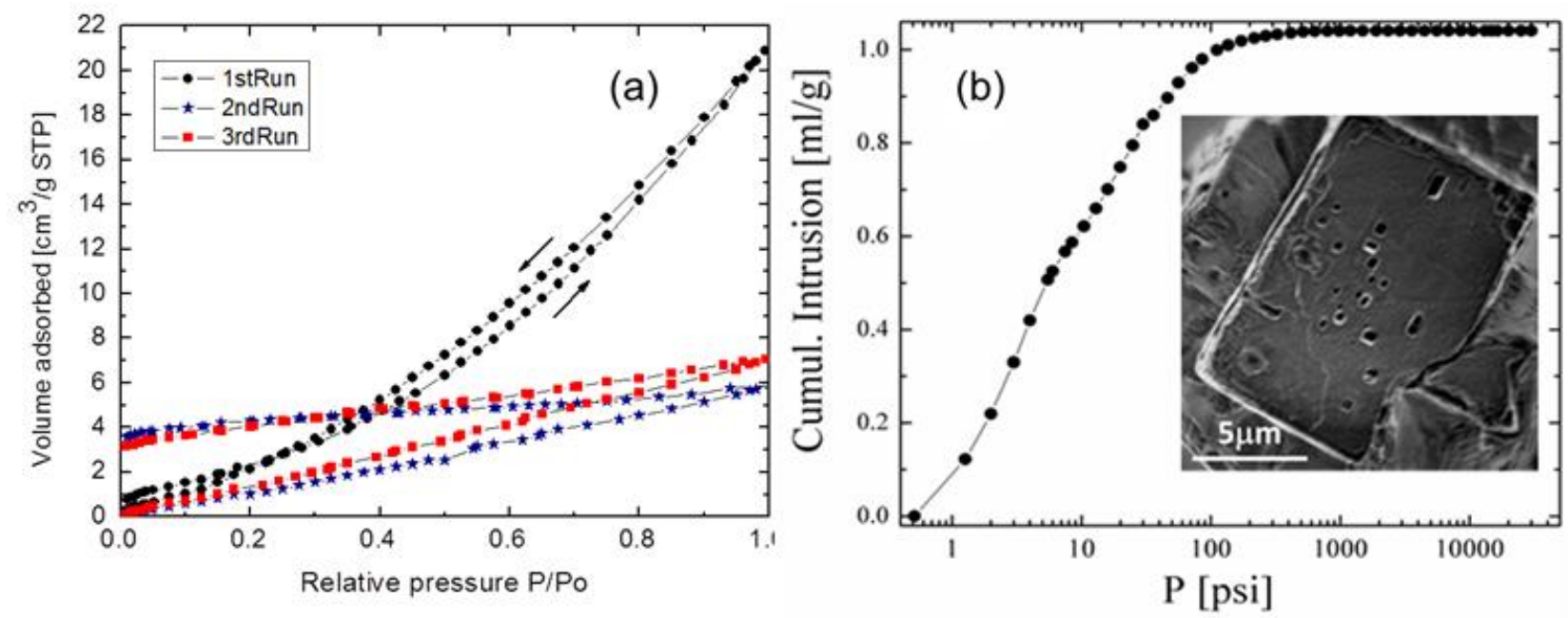

Figure 8(a) shows improved adsorption behavior of $4 . \mathrm{H}_{2(\mathrm{~g})}$ adsorption gradually raises to $21 \mathrm{~cm}^{3} / \mathrm{g}$ with increase of pressure. It not only bettered the earlier value but also shows narrow hysteretic reversibility. But again no preference for $\mathrm{N}_{2(\mathrm{~g})}$, which strengthens the hypothesis of size discrepancy discussed above. Consequent runs do not follow the same trend. It reduces to $\sim 6-7 \mathrm{~cm}^{3} / \mathrm{g}$ in second and third runs. Thus adsorption efficiency is not only reduced but also becomes irreversible. It is possible that, after the initial $\mathrm{H}_{2(\mathrm{~g})}$ sorption where the increasing pressure flexes-out the network to open the 'gate' to accommodate the guest, it keeps the network under stress and the subsequent desorption probably partially collapses the network while shrinking back. The retention of almost half of the adsorbed gas $\left(3 \mathrm{~cm}^{3} / \mathrm{g}\right)$ in second or third run after depressurization at low temperature although less, is interesting and such retentions are significant in systems which show high sorption-desorption property [103]. Square shaped openings (Figure 8(b)) discovered on the cubic crystal surface of 4 stimulated us to investigate the 'porosity partitioning' by Hg porosimetry [104,105]. Both techniques of gas adsorption and MIP rely upon balances between surface tension forces, capillary forces and pressure but their outcome may not be comparable due to distinctly different physical interactions involved in the two methods [106]. Figure 8(b) shows the volume of intruded $\mathrm{Hg}$ as a function of applied pressure. We recall that pressure is inversely proportional to the pore size according to Washburn equation (high pressures being necessary to fill small pores by inverted capillary effect) [107]. Mercury fills largest pores first, entering the smallest pores last under high pressure unlike gas adsorption. A fine analysis of Figure 8(b) allows identification of several steps. Indeed, as the pressure is gradually increased and as soon as it corresponds to a pore size, $\mathrm{Hg}$ enters the pores and a new step is recorded. When considering the pore size distribution (by applying the Washburn equation assuming constant contact angle and surface tension), the recorded steps can be understood as follows: the step between 1 and 5 psi corresponds to pores of $\sim 50 \mu \mathrm{m}$, between 10 and 25 psi to pores of about $6,000 \mathrm{~nm}$, between 30 and 80 psi to pores of about 2,000 $\mathrm{nm}$ and the remaining uptake between 100 and 500 psi reveals pores with sizes smaller than $350 \mathrm{~nm}$. After that, the curve reaches a 
plateau indicating that there are no smaller pores present. The major contributions at $50 \mu \mathrm{m}, 6,000 \mathrm{~nm}$ and 2,000 nm would rather originate from interparticular porosity, whereas the pores of $350 \mathrm{~nm}$ could correspond to the voids identified by SEM. These results thus illustrate the usefulness of $\mathrm{Hg}$ porosimetry for a complete porosity characterization in porous MOFs [53].

\subsection{Logistics for Network Constructions}

We have selected chiral and achiral derivatized amino acids in the construction of CP/MOFs. In the preceding sections we have seen how chiral HL4 resulted in a trinuclear network in centrosymmetic space group and achiral HL2 resulted in a 1D CP and a chiral helicate. Although the use of chiral molecules is the most common strategy $[108,109]$ for obtaining products with a non-centrosymmetric arrangement in the crystal lattice, it is not a rule. It is found that only $10-15 \%$ of achiral organic molecules crystallize in noncentrosymmetric space groups [108,109]. In contrast to the chiral amino acids, achiral glycine (as a structural unit) cannot enforce non-centrosymmetry [108] of a crystal structure. But its electronic and structural asymmetry together with consolidated effort of noncovalent interactions with suitable metal ions as connectors may lead to crystallization in a non-centrosymmetric space group. By using bridging ligands with a significant kink in the topology instead of linear rigid molecules, the formation of networks with a lower symmetry and helicity is possible [80,108]. The spontaneous helicity observed in $\mathbf{3}$ is due to the hierarchical self-assembly of the tiny synthon HL1 originating in non-centrosymmetric space group which falls into this category. The simple torsion angle count around the spacer in such molecules forms the basis of the assessment of molecular flexibility in them. Such conformationally flexible backbone and electronic asymmetry (push-pull effect) have high chances of ending up in a noncentrosymmetric space group, and such compounds have an enormous significance because of technological properties such as single harmonic generator (SHG), piezo-pyro-ferro electricity, triboluminescence [110]. Despite sharing common synthetic recipe $\mathbf{2}$ and $\mathbf{3}$ adopt totally different network formation. In $\mathbf{2}$, the carboxylic group is kept away from the coordination sphere unlike in $\mathbf{3}$ thus demonstrating role of synthetic method in directing network construction through self-assembly. This is a crucial point for the design of 1D coordination polymer involving switchable $\mathrm{Fe}^{\mathrm{II}}$ spin crossover ( $\mathrm{SCO}$ ) centers with a $\mathrm{MN}_{6}$ core [15-18]. A similar situation is also noticed in 1. Complex 1 is the first crystal structure of a triazole derivatized methionine complex, and also represents the first example of a neutral zinc trinuclear complex with three $N 1, N 2-1,2,4$-triazole bridges and without non-coordinated anion. It provides promising perspectives for computational studies in SCO research as it provides a model of a trinuclear diamagnetic complex without counter-anion while keeping the same size as high-spin $\mathrm{Fe}^{\mathrm{II}}$ ions [111].

On the other hand HL2 undergoes stunning self-assembly to form a 3D array of nanoball architecture in 4. The nanoporous void obtained in the present system is the artifact of angular framework of the ligand, thus hinting that fine tune of the void shape and size should be possible with variation of methylene ankle in the ligand and even impose network interpenetration. Further work is in progress to increase the void volume by replacing $\alpha$-amino acid by $\beta$-amino acid and $\gamma$-amino acid. The gas adsorption profile in $\mathbf{4}$ is not promising as the 'soft' skeleton of the ligand is not robust enough to withstand high temperature treatment of degassing. But in such systems in which axially bound water molecules can be easily removed, not necessarily thermally, that could possibly allow access to 
the Lewis acid sites for catalytic applications as nano-reactors for catalysis or anion/cation recognition. Another appealing perspective would concern the magnetic study of $\mathbf{4}$ in the frame of its potential spin frustration [112-115].

\subsection{Thermochromic Spin Crossover Materials}

The family of thermochromic 1D iron(II) 1,2,4-triazole spin crossover (SCO) coordination polymers have attracted our attention in recent years due to their promising prospects in the thriving field of molecular electronics [15-18]. Such triazole based precursors not only provide appropriate ligand field strength but also favors the formation of CPs due to its dominant $N 1, N 2$ bridging mode ending up in high dimensional networks which are recognized for their ability to efficiently propagate elastic cooperative effects associated to the SCO event [116]. Although SCO is well understood in $3 \mathrm{~d}^{4}-3 \mathrm{~d}^{7}$ transition metal ions in octahedral surrounding, the $3 \mathrm{~d}^{6}$ iron(II) complexes received greater attention [117]. In these compounds, the entropy driven reversible intra-ionic electron transfer from a diamagnetic low-spin ( $\mathrm{LS},{ }^{1} \mathrm{~A}_{1 \mathrm{~g}}$ ) state to a thermally populated paramagnetic high-spin $\left(\mathrm{HS},{ }^{5} \mathrm{~T}_{2 \mathrm{~g}}\right)$ state can be induced by external stimuli like temperature, pressure and light irradiation. In fact in the solid state, the presence of short and long range interactions acts as communication media between iron centers promoting cooperative first order spin transitions that can leads to a large memory domain that can be suitable for potential applications $[118,119]$. Indeed, a SCO compound meeting display and data processing requirements would have in addition a good shelf life and an easily detectable optical response, and would operate near room temperature [120]. In this context we recently introduced ethyl-4H-1,2,4-triazol-4-yl-acetate (L1) (Scheme 1) as a novel neutral bidentate ligand to synthesize a family of 1D SCO polymers [17]. Reaction of $\mathbf{L 1}$ with $\left[\mathrm{Fe}\left(\mathrm{H}_{2} \mathrm{O}\right)_{6}\right]\left(\mathrm{ClO}_{4}\right)_{2}$ in methanol afforded a white powder, which was dried under vacuum to lead to a desolvated compound $\left[\mathrm{Fe}(\mathrm{L} 1)_{3}\right]\left(\mathrm{ClO}_{4}\right)_{2}(\mathbf{5})$ whereas the same powder dried under stream of $\mathrm{N}_{2(\mathrm{~g})}$ afforded $\left[\mathrm{Fe}(\mathrm{L} 1)_{3}\right]\left(\mathrm{ClO}_{4}\right)_{2} \cdot \mathrm{MeOH}(\mathbf{6})$. The 1D polymeric nature of these compounds was confirmed by spectroscopic and analytical results. For $\mathbf{5}$, the temperature dependence of the high-spin molar fraction derived from ${ }^{57} \mathrm{Fe}$ Mossbauer spectroscopy reveals an exceptionally abrupt single step transition between LS and HS states with a hysteresis loop of width $5 \mathrm{~K}\left(T_{\mathrm{c}}{ }^{\uparrow}=298 \mathrm{~K}\right.$ and $\left.T_{\mathrm{c}}{ }^{\downarrow}=293 \mathrm{~K}\right)$. This spin transition operating around room temperature presents striking reversible thermochromism from white at $295 \mathrm{~K}$ to pink at ice temperature (Figure 9), thus behaving as an optical alert towards temperature variations [118]. Interestingly, the transition temperature of 6 is shifted to below room temperature $\left(T_{\mathrm{c}}{ }^{\uparrow}=273 \mathrm{~K}\right.$ and $\left.T_{\mathrm{c}}{ }^{\downarrow}=263 \mathrm{~K}\right)$, thus showing a remarkable influence of solvent inclusion on the spin state of these chain compounds. Efforts are underway to introduce $\beta$ and $\gamma$ amino acids and esters to investigate the influence of spacer on the SCO properties [56,57]. 
Figure 9. Selected ${ }^{57} \mathrm{Fe}$ Mossbauer spectra at $300 \mathrm{~K}$ and $78 \mathrm{~K}$ showing spin crossover and associated thermochromism in $\mathbf{5}$.
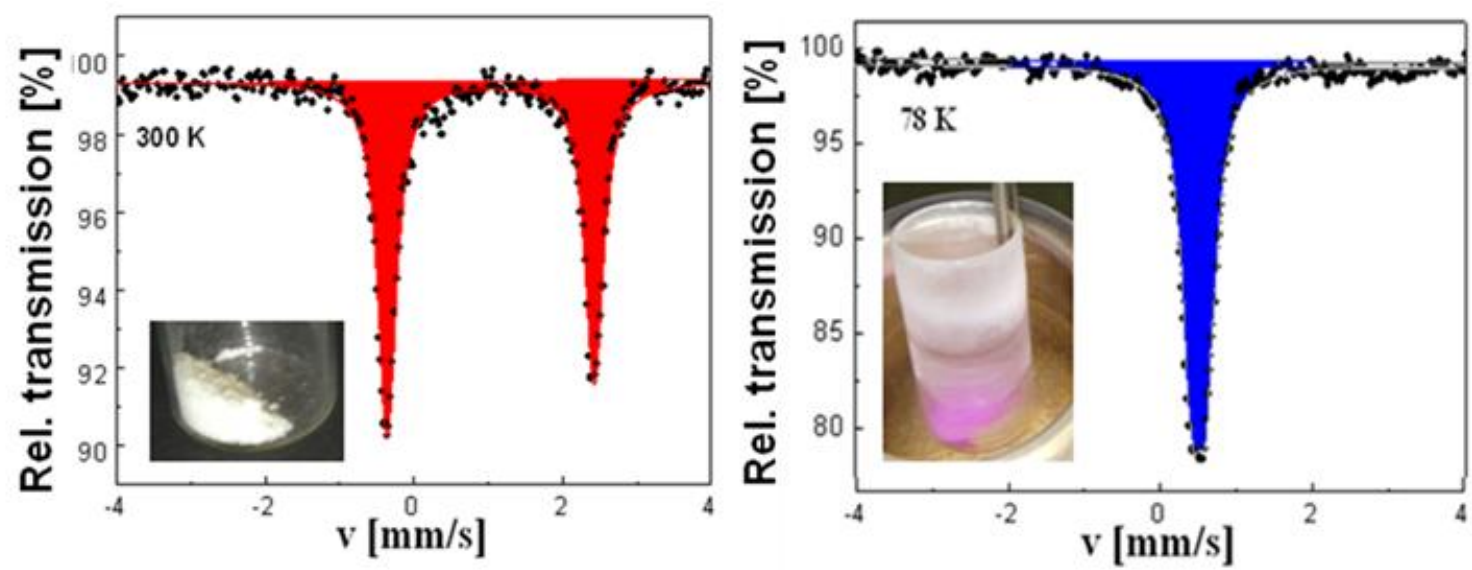

\section{Conclusions}

Undoubtedly amino acids are highly versatile templates among biomolecules to construct multifunctional high dimensional networks. Amine derivatization in amino acids to 1,2,4-triazoles provides natural and ideal topology, having synchronized conformational orientations of two reverent potential coordinating functional groups, namely carboxylic and triazole moieties on the same framework. This opens up a new juvenile impending way of heterocyclic derivatization in aminoacid chemistry that should find their way into the reticular chemistry synthon archive. This is particularly intriguing because different aminoacid derivatives can offer a virtually unlimited structural diversity and infinite array of network topologies in combination with metal ions across period table with possible extended applications in the area of catalysis, magnetism, chiral networks, spin crossover materials and medicinal chemistry.

\section{Acknowledgments}

We acknowledge financial support from IAP-VI (P6/17) INANOMAT, the Fonds National de la Recherche Scientifique (FNRS) (FRFC 2.4508.08, IISN 4.4507.10) and from a Concerted Research Action of the "Communauté Française de Belgique" allotted by the Académie Universitaire Louvain. J. Marchand-Brynaert is a senior research associate of the F.R.S.-FNRS (Belgium). We thank B. Tinant, B.-L. Su and A. Léonard for their continuing support.

\section{References}

1. Hoskins, B.F.; Robson, R.J. Infinite Polymeric Frameworks Consisting of Three Dimensionally Linked Rod-Like Segments. J. Am. Chem. Soc. 1989, 111, 5962-5964.

2. Li, H.; Eddaoudi, M.; O’Keeffe, M.; Yaghi, O.M. Design and Synthesis of an Exceptionally Stable and Highly Porous Metal-Organic Framework. Nature 1999, 402, 276-279.

3. Chae, H.; Siberio-Perez, D.Y.; Kim, J.; Go, Y.; Eddaoudi, M.; Matzger, A.; O’Keeffe, M.; Yaghi, O.M. A Route to High Surface Area, Porosity and Inclusion of Large Molecules in Crystals. Nature 2004, 427, 523-527. 
4. Eddaoudi, M.; Kim, J.; Rosi, N.; Vodak, D.; Wachter, J.; O’Keeffe, M.; Yaghi, O.M. Systematic Design of Pore Size and Functionality in Isoreticular MOFs and Their Application in Methane Storage. Science 2002, 295, 469-472.

5. Long, J.R.; Yaghi, O.M. The Pervasive Chemistry of Metal-Organic Frameworks. Chem. Soc. Rev. 2009, 38, 1213-1214.

6. Leong, W.L.; Vittal, J.J. One-Dimensional Coordination Polymers: Complexity and Diversity in Structures, Properties, and Applications. Chem. Rev. 2010, 111, 688-764.

7. Ferey, G. Hybrid Porous Solids: Past, Present, Future. Chem. Soc. Rev. 2008, 37, 191-214.

8. Kitagawa, S.; Kitaura, R.; Noro, S.I. Functional Porous Coordination Polymers. Angew. Chem. Int. Ed. 2004, 43, 2334-2375.

9. Horike, S.; Shimomura, S.; Kitagawa, S. Soft Porous Crystals. Nat. Chem. 2009, 1, 695-704.

10. Burrows, A.D.; Frost, C.G.; Mahon, M.F.; Richardson, C. Post-Synthetic Modification of Tagged Metal Organic Frameworks. Angew. Chem. Int. Ed. 2008, 47, 8482-8486.

11. Rosseinsky, M.J. Recent Developments in Metal-Organic Framework Chemistry: Design, Discovery, Permanent Porosity and Flexibility. Microporous Mesoporous Mater. 2004, 73, 15-30.

12. Kepert, C.J. Advanced Functional Properties in Nanoporous Coordination Framework Materials. Chem. Commun. 2006, 695-700.

13. Murray, L.J.; Dinca, M.; Long, J.R. Hydrogen Storage in Metal-Organic Frameworks. Chem. Soc. Rev. 2009, 38, 1294-1314.

14. Liang, L.L.; Ren, S.B.; Zhang, J.; Li, Y.Z.; Du, H.B.; You, X.Z. Two Unprecedented NLO-Active Coordination Polymers Constructed by a Semi-Rigid Tetrahedral Linker. Dalton Trans. 2010, 39, 7723-7726.

15. Dîrtu, M.M.; Rotaru, A.; Gillard, D.; Linares, J.; Codjovi, E.; Tinant, B.; Garcia, Y. Prediction of the Spin Transition Temperature in $\mathrm{Fe}^{\mathrm{II}}$ One-Dimensional Coordination Polymers: An Anion Based Database. Inorg. Chem. 2009, 48, 7838-7852.

16. Garcia, Y.; Ksenofontov, V.; Mentior, S.; Dîrtu, M.M.; Gieck, C.; Bhatthacharjee, A.; Gutlich, P. Rapid Cooling Experiments and Use of an Anionic Nuclear Probe to Sense the Spin Transition of the 1D Coordination Polymers $\left[\mathrm{Fe}\left(\mathrm{NH}_{2} \mathrm{trz}\right)_{3}\right] \mathrm{SnF}_{6} \cdot \mathrm{nH}_{2} \mathrm{O}\left(\mathrm{NH}_{2} \operatorname{trz}=4\right.$-amino-1,2,4-triazole $)$. Chem. Eur. J. 2008, 14, 3745-3758.

17. Dîrtu, M.M.; Naik, A.D.; Marchand-Brynaert, J.; Garcia, Y. Room Temperature Hysteretic Spin Transition in 1D Iron(II) Coordination Polymers. J. Phys. Conf. Ser. 2010, 217, 012085.

18. Garcia, Y.; Kahn, O.; Rabardel, L.; Chansou, B.; Salmon, L.; Tuchagues, J.P. Two-Step Spin Conversion for the Three-Dimensional Compound Tris(4,4'-bis-1,2,4-triazole)Iron(II) Diperchlorate. Inorg. Chem. 1999, 38, 4663-4670.

19. Cheng, X.N.; Zhang, W.X.; Lin, Y.Y.; Zheng, Y.Z.; Chen, X.M. A Dynamic Porous Magnet Exhibiting Reversible Guest-Induced Magnetic Behavior Modulation. Adv. Mater. 2007, 19, 1494-1498.

20. Forster, P.M.; Cheetham, A.K. Open-Framework Nickel Succinate, $\left[\mathrm{Ni}_{7}\left(\mathrm{C}_{4} \mathrm{H}_{4} \mathrm{O}_{4}\right)_{6}(\mathrm{OH})_{2}\left(\mathrm{H}_{2} \mathrm{O}\right)_{2}\right] 2 \mathrm{H}_{2} \mathrm{O}$ : A New Hybrid Material With Three-Dimensional Ni-O-Ni Connectivity. Angew. Chem. Int. Ed. 2002, 41, 457-459. 
21. Livage, C.; Guillou, N.; Chaigneau, J.; Rabu, P.; Drillon, M.; Férey, G. A Three-Dimensional Metal-Organic Framework with an Unprecedented Octahedral Building Unit. Angew. Chem. Int. Ed. 2005, 44, 6488-6491.

22. Maspoch, D.; Ruiz-Molina, D.; Wurst, K.; Domingo, N.; Cavallini, M.; Biscarini, F.; Tejada, J.; Rovira, C.; Veciana, J. A Nanoporous Molecular Magnet with Reversible Solvent-Induced Mechanical and Magnetic Properties. Nat. Mater. 2003, 2, 190-195.

23. Keskin, S.; Kizilel, S. Biomedical Applications of Metal Organic Frameworks. Indus. Eng. Chem. Res. 2011, 50, 1799-1812.

24. Liu, D.; Huxford, R.C.; Lin, W. Phosphorescent Nanoscale Coordination Polymers as Contrast Agents for Optical Imaging. Angew. Chem. Int. Ed. 2011, 50, 3696-3700.

25. Ma, Z.; Moulton, B. Recent Advances of Discrete Coordination Complexes and Coordination Polymers in Drug Delivery. Coord. Chem. Rev. 2011, 255, 1623-1641.

26. Ding, B.; Yi, L.; Cheng, P.; Liao, D.Z.; Yan, S.P. Synthesis and Characterization of a 3D Coordination Polymer Based on Trinuclear Triangular $\mathrm{Cu}^{\mathrm{II}}$ As Secondary Building Units. Inorg. Chem. 2006, 45, 5799-5803.

27. Ouellette, W.; Hudson, B.S.; Zubieta, J. Hydrothermal and Structural Chemistry of the Zinc(II)- and Cadmium(II)-1,2,4-Triazolate Systems. Inorg. Chem. 2007, 46, 4887-4904.

28. Ouellette, W.; Liu, H.; O'Connor, C.J.; Zubieta, J. Solid-State Coordination Chemistry of Copper(II) Tetrazolates: Anion Control of Frameworks Constructed from Trinuclear Copper(II) Building Blocks. Inorg. Chem. 2009, 48, 4655-4657.

29. Zhai, Q.G.; Lu, C.Z.; Chen, S.M.; Xu, X.J.; Yang, W.B. Design of Novel Three-Dimensional Coordination Polymers Based on Triangular Trinuclear Copper 1,2,4-Triazolate Units. Cryst. Growth Des. 2006, 6, 1393-1398.

30. Seo, J.S.; Whang, D.; Lee, H.; Jun, S.I.; Oh, J.; Jeon, Y.J.; Kim, K. A Homochiral Metal-Organic Porous Material for Enantioselective Separation and Catalysis. Nature 2000, 404, 982-986.

31. Zhang, J.P.; Chen, X.M. Exceptional Framework Flexibility and Sorption Behavior of a Multifunctional Porous Cuprous Triazolate Framework. J. Am. Chem. Soc. 2008, 130, 6010-6017.

32. Di Nicola, C.; Karabach, Y.Y.; Kirillov, A.M.; Monari, M.; Pandolfo, L.; Pettinari, C.; Pombeiro, A.J.L. Supramolecular Assemblies of Trinuclear Triangular Copper(II) Secondary Building Units Through Hydrogen Bonds. Generation of Different Metal-Organic Frameworks, Valuable Catalysts for Peroxidative Oxidation of Alkanes. Inorg. Chem. 2006, 46, 221-230.

33. Casarin, M.; Corvaja, C.; Di Nicola, C.; Falcomer, D.; Franco, L.; Monari, M.; Pandolfo, L.; Pettinari, C.; Piccinelli, F. One-Dimensional and Two-Dimensional Coordination Polymers from Self-Assembling of Trinuclear Triangular Cu(II) Secondary Building Units. Inorg. Chem. 2005, 44, 6265-6276.

34. Zhang, J.-J.; Sheng, T.-L.; Hu, S.-M.; Xia, S.-Q.; Leibeling, G.; Meyer, F.; Fu, Z.-Y.; Chen, L.; Fu, R.-B.; Wu, X.-T. Two 3D Supramolecular Polymers Constructed from an Amino Acid and a High-Nuclear Ln6Cu24 Cluster Node. Chem. Eur. J. 2004, 10, 3963-3969.

35. Ingleson, M.J.; Bacsa, J.; Rosseinsky, M.J. Homochiral H-Bonded Proline Based Metal Organic Frameworks. Chem. Commun. 2007, 3036-3038. 
36. Smaldone, R.A.; Forgan, R.S.; Furukawa, H.; Gassensmith, J.J.; Slawin, A.M. Z.; Yaghi, O.M.; Stoddart, J.F. Metal-Organic Frameworks from Edible Natural Products. Angew. Chem. Int. Ed. 2010, 49, 8630-8634.

37. Ranford, J.D.; Vittal, J.J.; Wu, D.; Yang, X. Thermal Conversion of a Helical Coil into a Three-Dimensional Chiral Framework. Angew. Chem. Int. Ed. 1999, 38, 3498-3501.

38. Anokhina, E.V.; Jacobson, A.J. [ $\left.\mathrm{Ni}_{2} \mathrm{O}(\mathrm{L}-\mathrm{Asp})\left(\mathrm{H}_{2} \mathrm{O}\right)_{2}\right] \cdot 4 \mathrm{H}_{2} \mathrm{O}$ : A Homochiral 1D Helical Chain Hybrid Compound With Extended Ni-O-Ni Bonding. J. Am. Chem. Soc. 2004, 126, 3044-3045.

39. Cutland-Van Noord, A.D.; Kampf, J.W.; Pecoraro, V.L. Preparation of Resolved Fourfold Symmetric Amphiphilic Helices Using Chiral Metallacrown Building Blocks. Angew. Chem. Int. Ed. 2002, 41, 4667-4670.

40. Alam, M.A.; Netaji, M.; Ray, M. Synthesis of a Self-Assembled Molecular Capsule That Traps Pyridine Molecules by a Combination of Hydrogen Bonding and Copper(II) Coordination. Angew. Chem. Int. Ed. 2003, 42, 1940-1942.

41. Chiou, S.-J.; Innocent, J.; Riordan, C.G.; Lam, K.-C.; Liable-Sands, L.; Rheingold, A.L. Synthetic Models for the Zinc Sites in the Methionine Synthases. Inorg. Chem. 2000, 39, 4347-4353.

42. Brand, U.; Rombach, M.; Seebacher, J.; Vahrenkamp, H. Functional Modeling of Cobalamine-Independent Methionine Synthase with Pyrazolylborate-Zinc-Thiolate Complexes. Inorg. Chem. 2001, 40, 6151-6157.

43. Patra, A.K.; Dhar, S.; Netaji, M.; Chakravarty, A.R. Visible Light-Induced Nuclease Activity of a Ternary Mono-Phenanthroline Copper(II) Complex Containing L-Methionine as a Photosensitizer. Chem. Commun. 2003, 1562-1563.

44. Tovar-Tovar, A.; R-Ramirez, L.; Campero, A.; Romerosa, A.; M-Esparza, R.; Rosales-Hoz, M.J. Structural and Reactivity Studies on 4,4'-Dimethyl-2,2'-Bipyridine Acetylacetonate Copper(II) Nitrate (CASIOPEINA III-Ia ${ }^{\circledR}$ ) With Methionine, by UV-Visible and EPR Techniques. J. Inorg. Biochem. 2004, 98, 1045-1053.

45. Sasmal, P.K.; Patra, A.K.; Nethaji, M.; Chakravarty, A.R. DNA Cleavage by New Oxovanadium(IV) Complexes of $\mathrm{N}$-Salicylidene a-Amino Acids and Phenanthroline Bases in the Photodynamic Therapy Window. Inorg. Chem. 2007, 46, 11112-11121.

46. Imaz, I.; Rubio-Martinez, M.; An, J.; Sole-Font, I.; Rosi, N.L.; Maspoch, D. Metal-Biomolecule Frameworks (MBioFs). Chem. Commun. 2011, 47, 7287-7302.

47. Rabone, J.; Yue, Y.F.; Chong, S.Y.; Stylianou, K.C.; Bacsa, J.; Bradshaw, D.; Darling, G.R.; Berry, N.G.; Khimyak, Y.Z.; Ganin, A.Y.; Wiper, P.; Claridge, J.B.; Rosseinsky, M.J. An Adaptable Peptide-Based Porous Material. Science 2010, 329, 1053-1057.

48. McKinlay, A.C.; Morris, R.E.; Horcajada, P.; Ferey, G.; Gref, R.; Couvreur, S.C. BioMOFs: Metal-Organic Frameworks for Biological and Medical Applications. Angew. Chem. Int. Ed. 2010, 49, 6260-6266.

49. Samsonenko, D.G.; Kim, H.; Sun, Y.; Kim, G.-H.; Lee, H.-S.; Kim, K. Microporous Magnesium and Manganese Formates for Acetylene Storage and Separation. Chem. Asian J. 2007, 2, 484-488. 
50. Serpaggi, F.; Ferey, G. Hybrid Open Frameworks (MIL-n). Part 4 Synthesis and Crystal Structure of MIL-8, a Series of Lanthanide Glutarates with an Open Framework, $\left[\mathrm{Ln}\left(\mathrm{H}_{2} \mathrm{O}\right)\right]_{2}\left[\mathrm{O}_{2} \mathrm{C}\left(\mathrm{CH}_{2}\right)_{3} \mathrm{CO}_{2}\right]_{3} \cdot 4 \mathrm{H}_{2} \mathrm{O}$. J. Mater. Chem. 1998, 8, 2737-2741.

51. Jhung, S.H.; Lee, J.-H.; Foster, P.M.; Ferey, G.; Cheetham, A.K.; Chang, J.-S. Microwave Synthesis of Hybrid Inorganic-Organic Porous Materials: Phase-Selective and Rapid Crystallization. Chem. Eur. J. 2006, 12, 7899-7905.

52. Naik, A.D.; Marchand-Brynaert, J.; Garcia, Y. A Simplified Approach to N- and N,N'-Linked 1,2,4-Triazoles by Transamination. Synthesis 2008, 1, 149-154.

53. Naik, A.D.; Dîrtu, M.M.; Leonard, A.; Tinant, B.; Marchand-Brynaert, J.; Su, B.L.; Garcia, Y. Engineering Three-Dimensional Chains of Porous Nanoballs from a 1,2,4-Triazole-Carboxylate Supramolecular Synthon. Cryst. Growth Des. 2010, 10, 1798-1807.

54. Naik, A.D.; Beck, J.; Dîrtu, M.M.; Bebrone, C.; Tinant, B.; Robeyns, K.; Marchand-Brynaert, J.; Garcia, Y. Zinc Complexes with 1,2,4-Triazole Functionalized Amino Acid Derivatives: Synthesis, Structure and $\beta$-Lactamase Assay. Inorg. Chim. Acta 2011, 368, 21 28.

55. Dîrtu, M.M.; Neuhausen, C.; Naik, A.D.; Leonard, A.; Robert, F.; Marchand-Brynaert, J.; Su, B.L.; Garcia, Y. Superlative Scaffold of 1,2,4-Triazole Derivative of Glycine Steering Linear Chain to a Chiral Helicate. Cryst. Growth Des. 2011, 11, 1375-1384.

56. Dîrtu, M.M.; Schmit, F.; Naik, A.D.; Rotaru, A.; Marchand-Brynaert, J.; Garcia, Y. Spin Transition Sensors based on $\beta$-amino-acid 1,2,4-Triazole Derivative. Int. J. Mol. Sci. 2011, 12 , 5339-5351.

57. Railliet, A.P.; Naik, A.D.; Rotaru, A.; Marchand-Brynaert, J.; Garcia, Y. 1D Iron(II) Spin Crossover Complexes with 1,2,4-triazol-4-yl-propanoic acid. Hyperfine Interact. 2011, in press.

58. Bayer, H.O.; Cook, R.S.; Von Meyer, W.C. Fungicidal Use of a 1.2,4-Triazole Nickel Salt Complex. U.S. Patent 3,821,376, 12 January 1974.

59. Heinz, U.; Adolph, H.-W. Metallo-ß-Lactamases: Two Binding Sites for One Catalytic Metal Ion? Cell. Mol. Life Sci. 2004, 61, 2827-2839.

60. Spek, A.L.; Vos, G. Structure of $a, b, c, j, k, l$-Hexaaqua- $d, e, f, g, h, i$-Hexakis[ $\mu$-(4-Ethyl-1,2,4-Triazole$\left.\left.N^{1}, N^{2}\right)\right]$ Trizinc(II) Hexakis(Trifluoromethanesulphonate), $\left[\mathrm{Zn}_{3}\left(\mathrm{C}_{4} \mathrm{H}_{7} \mathrm{~N}_{3}\right)_{6}\left(\mathrm{H}_{2} \mathrm{O}\right)_{6}\right]\left[\mathrm{CF}_{3} \mathrm{SO}_{3}\right]_{6}$. Acta Crystallogr. C 1983, 39, 990-993.

61. Alagar, M.; Krishnakumar, R.V.; Mostad, A.; Natarajan, S. $\beta$-DL-Methionine at 105 K. Acta Crystallogr. E 2005, 61, o1165-o1167.

62. Natarajan, S.; Devi, N.R.; Dhas, S.D.M.B.; Athimoolam, S. Crystal Growth and Structure of L-Methionine L-Methioninium Hydrogen Maleate-A New NLO Material. Sci. Technol. Adv. Mater. 2008, 9, 025012.

63. Rothenburger, C.; Galanski, M.; Arion, V.B.; Gorls, H.; Weigand, W.; Keppler, B.K. Synthesis and Characterization of [(1R,2R)-Trans-Diaminocyclohexane]Platinum(II) Coordinated to Sulfur and Selenium Amino Acids. Eur. J. Inorg. Chem. 2006, 2006, 3746-3752.

64. Luo, T.T.; Hsu, L.-Y.; Su, C.-C.; Ueng, C.-H.; Tsai, T.-C.; Lu, K.-L. Deliberate Design of a 3D Homochiral CuII/l-Met/AgI Coordination Network Based on the Distinct Soft-Hard Recognition Principle. Inorg. Chem. 2007, 46, 1532-1534. 
65. Taylor, R.; Kennard, O.; Versichel, W. Geometry of the Nitrogen-Hydrogen...Oxygen-Carbon (N-H...O:C) Hydrogen Bond. 2. Three-Center (Bifurcated) and Four-Center (Trifurcated) Bonds. J. Am. Chem. Soc. 1984, 106, 244-248.

66. Tamilselvi, A.; Mugesh, G. Zinc and Antibiotic Resistance: Metallo-ß-Lactamases and Their Synthetic Analogues. J. Biol. Inorg. Chem. 2008, 13, 1039-1053.

67. Tamilselvi, A.; Nethaji, M.; Mugesh, G. Antibiotic Resistance: Mono- and Dinuclear Zinc Complexes as Metallo-ß-Lactamase Mimics. Chem. Eur. J. 2006, 12, 7797-7806.

68. Haasnoot, J.G. Mononuclear, Oligonuclear and Polynuclear Metal Coordination Compounds with 1,2,4-Triazole Derivatives as Ligands. Coord. Chem. Rev. 2000, 200, 131-185.

69. Zhai, Q.-G.; Wu, X.-Y.; Chen, S.-M.; Lu, C.-Z.; Yang, W.B. Construction of Cd/Zn(II)-1,2,4Triazolate Coordination Complexes via Changing Substituents and Anions. Cryst. Growth Des. 2006, 6, 2126-2135.

70. Zhai, Q.G.; Lu, C.Z.; Wu, X.Y.; Batten, S.R. Coligand Modulated Six-, Eight-, and Ten-Connected Zn/Cd-1,2,4-Triazolate Frameworks Based on Mono-, Bi-, Tri-, Penta-, and Heptanuclear Cluster Units. Cryst. Growth Des. 2007, 7, 2332-2342.

71. Yi, L.; Ding, B.; Cheng, P.; Liao, D.-Z.; Yan, S.-P.; Jiang, Z.-H. Novel Triazole-Bridged Cadmium Coordination Polymers Varying from Zero- to Three-Dimensionality. Inorg. Chem. 2003, 43, 33-43.

72. Marchivie, M.; Guionneau, P.; Letard, J.F.; Chasseau, D. Photo-Induced Spin-Transition: The Role of the Iron(II) Environment Distortion. Acta Crystallogr. B 2005, 61, 25-28.

73. Garcia, Y.; van Koningsbruggen, P.J.; Bravic, G.; Chasseau, D.; Kahn, O.A Cu Chain Compound Showing a Ferromagnetic Coupling through Triple N1,N2-1,2,4-Triazole Bridges. Eur. J. Inorg. Chem. 2003, 356-362.

74. Siddiqui, K.A.; Bolte, M.; Mehrotra, G.K. Triazole Based Cadmium(II) Anionic Framework With 2-Dimensional Helical Channels: Ionic Liquid Induced Synthesis. Inorg. Chim. Acta 2010, $363,457-463$.

75. Chen, Z.; Li, X.; Liang, F. Four Zn(II)/Cd(II)-3-amino-1,2,4-triazolate Frameworks Constructed by in Situ Metal/Ligand Reactions: Structures and Fluorescent Properties. J. Solid State Chem. 2008, 181, 2078-2086.

76. Maeda, K.; Yashima, E. Supramolecular Chirality—Dynamic Helical Structures: Detection and Amplification of Chirality. Top. Curr. Chem. 2006, 265, 44-88.

77. Scarso, A.; Rebek, J., Jr. Supramolecular Chirality-Chiral Spaces in Supramolecular Assemblies. Top. Curr. Chem. 2006, 265, 1-46.

78. Seeber, G.; Tiedemann, B.E.F.; Raymond, K.N. Supramolecular Chirality—Supramolecular Chirality in Coordination Chemistry. Top. Curr. Chem. 2006, 265, 147-183.

79. Knof, U.; Zelewsky, A.V. Predetermined Chirality at Metal Centers. Angew. Chem. Int. Ed. 1999, 38, 302-322.

80. Maggard, P.A.; Stern, C.L.; Poeppelmeier, K.R. Understanding the Role of Helical Chains in the Formation of Noncentrosymmetric Solids. J. Am. Chem. Soc. 2001, 123, 7742-7743.

81. Eggert, J.P.W.; Harrowfield, J.; Lüning, U.; Skelton, B.W.; White, A.H.; Löffler, F.; Konrad, S. Improved Synthesis and Conformational Analysis of an A, D-1,10-Phenanthroline-Bridged Calix[6]Arene. Eur. J. Org. Chem. 2005, 2005, 1348-1353. 
82. Yu, Q.; Zhang, X.; Bian, H.; Liang, H.; Zhao, B.; Yan, S.; Liao, D. PH-Dependent Cu(II) Coordination Polymers with Tetrazole-1-Acetic Acid: Synthesis, Crystal Structures, EPR and Magnetic Properties. Cryst. Growth Des. 2008, 8, 1140-1146.

83. Addison, A.W.; Rao, T.N.; Reedijk, J.; Van Rijn, J.; Verschoor, G.C. Synthesis, Structure, and Spectroscopic Properties of Copper(II) Compounds Containing Nitrogen-Sulphur Donor Ligands; the Crystal and Molecular Structure of Aqua[1,7-Bis(N-Methylbenzimidazol-2[Prime or Minute]-Y1)-2,6-Dithiaheptane]Copper(II) Perchlorate. J. Chem. Soc. Dalton Trans. 1984, 1349-1356.

84. Perry, J.J., IV; Perman, J.A.; Zaworotko, M. Design and Synthesis of Metal-Organic Frameworks Using Metal-Organic Polyhedra as Supermolecular Building Blocks. Chem. Soc. Rev. 2009, 38, 1400-1417.

85. Fletcher, A.J.; Thomas, M.K.; Rosseinsky, J.M. Flexibility in Metal-Organic Framework Materials: Impact on Sorption Properties. J. Solid State Chem. 2005, 178, 2491-2510.

86. Macheboeuf, P.; Contreras-Martel, C.; Job, V.; Dideberg, O.; Dessen, A. Penicillin Binding Proteins: Key Players in Bacterial Cell Cycle and Drug Resistance Processes. FEMS Microbiol. Rev. 2006, 30, 673-691.

87. Bryskier, A.; Couturier, C.; Lowther, J. B-Lactamase Inhibitors under Research. Antimicrob. Agents Chemother. 2011, 55, 410-446.

88. Beck, J.; Maton, L.; Habib Jiwan, J.L.; Marchand-Brynaert, J. Calcium and Zinc Complexes of Pyrroglutamate Analogs Detected by Electrospray Ionization Mass Spectrometry. Amino acids 2011, 40, 679-687.

89. Badarau, A.; Page, M.I. The Variation of Catalytic Efficiency of Bacillus Cereus Metallo-ß-Lactamase with Different Active Site Metal Ions. Biochemistry 2006, 45, 10654-10666.

90. Hernandez Valladares, M.; Felici, A.; Weber, G.; Adolph, H.W.; Zeppezauer, M.; Rossolini, G.M.; Amicosante, G.; Frère, J.M.; Galleni, M. Zn(II) Dependence of the Aeromonas Hydrophila AE036 Metallo-ß-Lactamase Activity and Stability. Biochemistry 1997, 36, 11534-11541.

91. Ullah, J.H.; Walsh, T.R.; Taylor, I.A.; Emery, D.C.; Verma, C.S.; Gamblin, S.J.; Spencer, J. The Crystal Structure of the L1 Metallo- $\beta$-Lactamase From Stenotrophomonas Maltophilia at 1.7 A Resolution. J. Mol. Biol. 1998, 284, 125-136.

92. Bebrone, C. Metallo- $\beta$-Lactamases (Classification, Activity, Genetic Organization, Structure, Zinc Coordination) and Their Superfamily. Biochem. Pharm. 2007, 74, 1686-1701.

93. Llarrull, L.I.; Tioni, M.F.; Kowalski, J.; Bennett, B.; Vila, A.J. Evidence for a Dinuclear Active Site in the Metallo- $\beta$-Lactamase BcII With Substoichiometric Co(II): A New model for metal uptake. J. Biol. Chem. 2007, 282, 30586-30595.

94. Ghoshal, T.B.S.; Nambissan, P.M. G.; Majumdar, G.; De, S.K. Cadmium Oxide Octahedrons and Nanowires on the Micro-Octahedrons: A Simple Solvothermal Synthesis. Cryst. Growth Des. 2009, 9, 1287-1292.

95. Koparanova, N.; Zlatev, Z.; Genchev, D.; Popovich, G.J. Cadmium Oxide Whisker Crystals Grown by the Vapour-Liquid-Solid Mechanism Using Various Elements as Growth Initiators. J. Mater. Sci. 1994, 29, 103-109. 
96. Shi, W.; Wang, C.; Wang, H.; Zhang, H. Hexagonal Nanodisks of Cadmium Hydroxide and Oxide with Nanoporous Structure. Cryst. Growth Des. 2006, 6, 915-918.

97. Pan, Z.W.; Dai, Z.R.; Wang, Z.L. Nanobelts of Semiconducting Oxides. Science 2001, 291, 1947-1949.

98. Jia, Z.; Tang, Y.; Luo, L.; Li, B. Shape-Controlled Synthesis of Single-Crystalline $\mathrm{CdCO}_{3}$ and Corresponding Porous CdO Nanostructures. Cryst. Growth Des. 2008, 8, 2116-2120.

99. Kim, J.H.; Hong, Y.C.; Uhm, H.S. Direct Synthesis and Characterization of CdO Nano-Cubes. Jpn. J. Appl. Phys. 2007, 46, 4351-4354.

100. Ghosh, M.; Rao, C.N.R. Solvothermal Synthesis of $\mathrm{CdO}$ and $\mathrm{CuO}$ Nanocrystals. Chem. Phys. Lett. 2004, 393, 493-497.

101. Yu, H.; Wang, D.; Han, M.-Y.J. Top-Down Solid-Phase Fabrication of Nanoporous Cadmium Oxide Architectures. J. Am. Chem. Soc. 2007, 129, 2333-2337.

102. Lee, H.J.; Cho, W.; Jung, S.; Oh, M. Morphology-Selective Formation and Morphology-Dependent Gas-Adsorption Properties of Coordination Polymer Particles. Adv. Mater. 2009, 21, 674-677.

103. Zhao, X.; Xiao, B.; Fletcher, A.J.; Thomas, K.M.; Barshaw, D.; Rosseinsky, M.J.; Zhao, X.; Xiao, B.; Fletcher, A.J.; Thomas, K.M.; Barshaw, D.; Rosseinsky, M.J. Hysteretic Adsorption and Desorption of Hydrogen by Nanoporous Metal-Organic Frameworks. Science 2004, 306, 1012-1015.

104. Giesche, H. Mercury Porosimetry: A General (Practical) Overview. Part. Part. Syst. Charact. 2006, 23, 9-19.

105. Giesche, H. Handbook of Porous Solids; Schüth, F., Sing, K.S.W., Weitkamp, J., Eds.; WILEY-VCH Verlag GmbH: Berlin, Germany, 2002; Chapter 1.

106. Webb, P.A.; Orr, C.; Camp, R.W.; Olivier J.P. Analytical Methods in Fine Particle Technology; Micromeritics Instrument Corp.: Norcross, GA, USA, 1997.

107. Washburn, E.W. The Dynamics of Capillary Flow. Phys. Rev. 1921, 17, 273-283.

108. Saha, B.K.; Nangia, A.; Nicoud, J.F. Using Halogen-Halogen Interactions to Direct Noncentrosymmetric Crystal Packing in Dipolar Organic Molecules. Crystal Growth Des. 2006, 6, 1278-1281.

109. Pidcock, E. Achiral Molecules in Non-Centrosymmetric Space Groups. Chem. Comm. 2005, 3457-3459.

110. Holman, K.T.; Pivovar, A.M.; Ward, M.D. Engineering Crystal Symmetry and Polar Order in Molecular Host Frameworks. Science 2001, 294, 1907-1911.

111. Wolny, J.A.; Rackiwtz, S.; Achterhold, K.; Garcia, Y.; Muffler, K.; Naik, A.D.; Schunemann, V. Vibrational Properties of the Trinuclear Spin Crossover Complex [Fe $\mathrm{Fe}_{3}$ (4-(2'-hydroxy-ethyl)-1,2,4-triazole $\left.)_{6}\left(\mathrm{H}_{2} \mathrm{O}\right)_{6}\right]\left(\mathrm{CF}_{3} \mathrm{SO}_{3}\right)_{6}$ : A Nuclear Inelastic Scattering, IR, Raman and DFT Study. Phys. Chem. Chem. Phys. 2010, 12, 14782-14788. 
112. Ferrer, S.; Lloret, F.; Bertomeu, I.; Alzuet, G.; Borras, J.; Garcia-Granda, S.; Liu-Gonzalez, M.; Haasnoot, J.G. Cyclic Trinuclear and Chain of Cyclic Trinuclear Copper(II) Complexes Containing a Pyramidal $\mathrm{Cu}_{3} \mathrm{O}(\mathrm{H})$ Core. Crystal Structures and Magnetic Properties of $\left[\mathrm{Cu}_{3}\left(\mu_{3}-\mathrm{OH}\right)(\text { aaat })_{3}\left(\mathrm{H}_{2} \mathrm{O}\right)_{3}\right]\left(\mathrm{NO}_{3}\right)_{2} \mathrm{H}_{2} \mathrm{O}$ [aaat = 3-Acetylamino-5-Amino-1,2,4-Triazolate $]$ and $\left\{\left[\mathrm{Cu}_{3}\left(\mu_{3}-\mathrm{OH}\right)(\text { aat })_{3}\left(\mu_{3} \mathrm{SO}_{4}\right)\right] \cdot 6 \mathrm{H}_{2} \mathrm{O}\right\}_{n}$ [aat = 3-Acetylamino-1,2,4-Triazolate]: New Cases of Spin-Frustrated Systems. Inorg. Chem. 2002, 41, 5821-5830.

113. Sarkar, B.; Ray, M.S.; Drew, M.G.B.; Figuerola, A.; Diaz, C.; Ghosh, A. Trinuclear Cu(II) Complexes Containing Peripheral Ketonic Oxygen Bridges and a $\mu_{3}-\mathrm{OH}$ Core: Steric Influence on Their Structures and Existence. Polyhedron 2006, 25, 3084-3094.

114. Mukherjee, P.; Drew, M.G.B.; Estrader, M.; Diaz, C.; Ghosh, A. Influence of Counter Anions on the Structures and Magnetic Properties of Trinuclear $\mathrm{Cu}(\mathrm{II})$ Complexes Containing a $\mu_{3}-\mathrm{OH}$ Core and Schiff Base Ligands. Inorg. Chim. Acta 2008, 361, 161-172.

115. Ray, M.S.; Chattopadhyay, S.; Drew, M.G.B.; Figuerola, A.; Ribas, J.; Diaz, C.; Ghosh, A. Trinuclear $\mathrm{Cu}^{\mathrm{II}}$ Complexes Containing Peripheral Ketonic Oxygen Bridges and a $\mu_{3}-\mathrm{OH}$ Core: Syntheses, Crystal Structures, Spectroscopic and Magnetic Properties. Eur. J. Inorg. Chem. 2005, 22, 4562-4571.

116. Garcia, Y.; Niel, V.; Muñoz, M.C.; Real, J.A. Spin Crossover in 1D, 2D and 3D Polymeric Fe(II) Networks. Top. Curr. Chem. 2004, 233, 229-257.

117. Gütlich, P.; Garcia, Y.; Spiering, H. Magnetism: From Molecules to Materials; Wiley-VCH, Verlag GmbH: Berlin, Germany, 2003; p. 271.

118. Kahn, O.; Jay-Martinez, C. Spin-Transition Polymers: From Molecular Materials toward Memory Devices. Science 1998, 279, 44-48.

119. Garcia, Y.; Ksenofontov, V.; Gütlich, P. Spin Transition Molecular Materials: New Sensors. Hyperfine Interact. 2002, 139/140, 543-551.

120. Kahn, O.; Kröber, J.; Jay, C. Spin Transition Molecular Materials for Displays and Data Recording. Adv. Mater. 1992, 4, 718-728.

(C) 2011 by the authors; licensee MDPI, Basel, Switzerland. This article is an open access article distributed under the terms and conditions of the Creative Commons Attribution license (http://creativecommons.org/licenses/by/3.0/). 